\title{
Extinction of Aversive Memories Associated with Morphine Withdrawal Requires ERK-Mediated Epigenetic Regulation of Brain-Derived Neurotrophic Factor Transcription in the Rat Ventromedial Prefrontal Cortex
}

\author{
Wei-Sheng Wang, ${ }^{1 \star}$ Shuo Kang, ${ }^{1 *}$ Wen-Tao Liu, ${ }^{2} \mathrm{Mu}$ Li, ${ }^{1}$ Yao Liu, ${ }^{1}$ Chuan Yu, ${ }^{1}$ Jie Chen, ${ }^{1}$ Zhi-Qiang Chi, ${ }^{1}$ Ling He, ${ }^{2}$ \\ and Jing-Gen Liu ${ }^{1}$ \\ ${ }^{1}$ State Key Laboratory of Drug Research, Shanghai Institute of Materia Media, Chinese Academy of Sciences, Shanghai 201203, China, and ${ }^{2}$ Department of \\ Pharmacology, China Pharmaceutical University, Nanjing 210009, China
}

\begin{abstract}
Recent evidence suggests that histone deacetylase (HDAC) inhibitors facilitate extinction of rewarding memory of drug taking. However, little is known about the role of chromatin modification in the extinction of aversive memory of drug withdrawal. In this study, we used conditioned place aversion (CPA), a highly sensitive model for measuring aversive memory of drug withdrawal, to investigate the role of epigenetic regulation of brain-derived neurotrophic factor (BDNF) gene expression in extinction of aversive memory. We found that CPA extinction training induced an increase in recruiting cAMP response element-binding protein (CREB) to and acetylation of histone $\mathrm{H} 3$ at the promoters of BDNF exon I transcript and increased BDNF mRNA and protein expression in the ventromedial prefrontal cortex (vmPFC) of acute morphine-dependent rats and that such epigenetic regulation of BDNF gene transcription could be facilitated or diminished by intra-vmPFC infusion of HDAC inhibitor trichostatin A or extracellular signal-regulated kinase (ERK) inhibitor U0126 (1,4-diamino-2,3-dicyano-1,4-bis(methylthio)butadiene) before extinction training. Correspondingly, disruption of the epigenetic regulation of BDNF gene transcription with U0126 or suppression of BDNF signaling with Trk receptor antagonist K252a or BDNF scavenger tyrosine kinase receptor B (TrkB)-Fc blocked extinction of CPA behavior. We also found that extinction training-induced activation of ERK and CREB and extinction of CPA behavior could be potentiated or suppressed by intra-vmPFC infusion of D-cycloserine, a NMDA receptor partial agonist or aminophosphonopentanoic acid, a NMDA receptor antagonist. We conclude that extinction of aversive memory of morphine withdrawal requires epigenetic regulation of BDNF gene transcription in the vmPFC through activation of the ERK-CREB signaling pathway perhaps in a NMDA receptor-dependent manner.
\end{abstract}

\section{Introduction}

Opiate addiction is the chronic relapsing disorder characterized by compulsive drug taking (De Vries and Shippenberg, 2002). Conditioned reinforcement may play a crucial role in loss of control over drug taking and relapse after abstinence. Increasing evidence shows that negative reinforcement resulting from the aversive affective consequences of opiate withdrawal can enhance the incentive value of the drug and contribute to the maintenance of drug seeking behavior (Hutcheson et al., 2001; Koob and Le Moal, 2005; Kenny et al., 2006). Conditioned place aversion (CPA) is a highly sensitive animal model for measurement of the

Received April 25, 2012; revised Aug. 2, 2012; accepted Aug. 10, 2012.

Author contributions: W.-S.W., Z.-Q.C., L.H., and J.-G.L. designed research;W.-S.W., S.K., W.-T.L., Y.L., C.Y., and J.C. performed research; W.-S.W., M.L., and J.-G.L. analyzed data; W.-S.W. and J.-G.L. wrote the paper.

*W.-S.W. and S.K. contributed equally to this work.

This research was supported by Grants 2009CB522005, 2012ZX09301001-005, and 2008BAI49B05 (to J.-G.L.) from the Ministry of Science and Technology of China and by Grant 81130087 (to J.-G.L.) from the Foundation of National Natural Science of China.

Correspondence should be addressed to Jing-Gen Liu, State Key Laboratory of Drug Research, Shanghai Institute of Materia Medica, Chinese Academy of Sciences, Shanghai 201203, China. E-mail: jgliu@mail.shcnc.ac.cn.

DOI:10.1523/JNEUROSCI.1991-12.2012

Copyright $\odot 2012$ the authors $\quad 0270-6474 / 12 / 3213763-13 \$ 15.00 / 0$ negative affective components of opiate withdrawal (Stinus et al., 2000; Azar et al., 2003) and it develops through associative learning and requires synaptic plasticity (Hou et al., 2009). Extinction therapy has been proposed as a method to reduce the motivational impact of drug-associated cues to prevent relapse (Taylor et al., 2009). There is much information about the neurobiological mechanism of extinction of reward memory of drug taking (Feltenstein and See, 2007; Hsu and Packard, 2008; Torregrossa et al., 2010). However, as yet little information is known about extinction of aversive memory of drug withdrawal (Myers and Carlezon, 2010). Understanding the mechanisms underlying extinction of aversive memories of drug withdrawal could lead to pharmacological approaches for enhancing extinction memory, which might facilitate the treatment of drug addiction.

Extinction is a form of new learning that inhibits the original memory. Studies have suggested that the molecular mechanisms of extinction are similar to those that underlie initial associative learning (Quirk and Mueller, 2008). Recent evidence suggests the regulation of transcription via chromatin modification appears to be a major molecular mechanism for the formation and/or consolidation of drug associated memories and may contribute 
to the formation and persistence of drug-seeking behaviors ( $\mathrm{Ku}$ mar et al., 2005; Levine et al., 2005; Renthal et al., 2007; Romieu et al., 2008; Malvaez et al., 2011). Recent studies also suggest that epigenetic mechanisms have an important role in extinction of drug-seeking behaviors. It has been demonstrated that systematic administration of the histone deacetylase (HDAC) inhibitors following exposure to the previously drug-paired context facilitates extinction of drug-induced conditioned place preference (CPP) and reduces reinstatement of CPP after subsequent drug exposure (Malvaez et al., 2010; Wang et al., 2010). Although these two elegant studies demonstrate involvement of chromatin modification in extinction of positive affective memory of drug taking, little is known about epigenetic regulation of gene transcription in extinction of aversive memory associated with drug withdrawal.

Accumulating evidence indicates that the ventromedial prefrontal cortex (vmPFC) is critical for the extinction of fear and drug-seeking behaviors (Peters et al., 2009). Recent evidence shows that epigenetic regulation of the gene encoding brainderived neurotrophic factor (BDNF) within the medial prefrontal cortex (mPFC) correlates with fear extinction (Bredy et al., 2007) and attenuating the reinforcing efficacy of cocaine (SadriVakili et al., 2010). Accordingly, exogenous BDNF infusions into the mPFC suppress the reinstatement of cocaine seeking (Berglind et al., 2007, 2009; McGinty et al., 2010; Whitfield et al., 2011). These studies raise the possibility that epigenetic regulation of the gene encoding BDNF within the mPFC might be implicated in extinction of reward memory of drug taking or aversive memory of drug withdrawal. Therefore, this study used CPA paradigm to investigate the role of chromatin modification within vmPFC of BDNF mRNA expression in extinction of aversive affective memory associated with drug withdrawal.

\section{Materials and Methods}

\section{Subjects}

Sprague Dawley male rats weighing 220-250 g were obtained from the Laboratory Animal Center, Chinese Academy of Sciences (Shanghai, China). Rats were housed three per cage and maintained on a $12 \mathrm{~h}$ light/ dark cycle with access to food and water ad libitum. All experimental procedures were in strict accordance with the National Institutes of Health Guide for the Care and Use of Laboratory Animals.

\section{Surgery}

Rats (weighing 270-300 g when surgery began) were anesthetized with sodium pentobarbital anesthesia $(55 \mathrm{mg} / \mathrm{kg}$, i.p.), treated with atropine sulfate $(0.2 \mathrm{mg} / \mathrm{kg}$, i.p. $)$ and then placed in a stereotaxic apparatus (Narishige). Rats were implanted bilaterally with guide cannulae in the ventromedial prefrontal cortex [anteroposterior (AP), $+2.8 \mathrm{~mm}$; mediolateral (ML), $\pm 0.6 \mathrm{~mm}$; dorsoventral (DV), $-3.5 \mathrm{~mm}$ ). The cannulas were anchored to the skull with stainless steel screws and dental cement. A stainless steel blocker was inserted into each cannula to keep them patent and prevent infection. The rats were allowed to recover from surgery for $3-5 \mathrm{~d}$.

Intracerebral microinjection. Each infusion volume was $0.5 \mu \mathrm{l}$ per side infused at a rate of $0.25 \mu \mathrm{l} / \mathrm{min}$. Bilateral microinfusions were made through 31 gauge injection cannulae $(1.0 \mathrm{~mm}$ beyond the tip of guide cannulae) that was connected to a $10 \mu \mathrm{l}$ microsyringe mounted in the microinfusion pump (Harvard Apparatus), and the drugs were infused into the vmPFC over $2 \mathrm{~min}$ and given an additional 2 min for drug diffusion.

U0126 (1,4-diamino-2,3-dicyano-1,4-bis(methylthio)butadiene) and Trichostatin A were bilaterally microinjected into the vmPFC $20 \mathrm{~min}$ before extinction; D-cycloserine, K252a and TrkB-FC were bilaterally injected into the vmPFC immediately after extinction training.

TrkB-FC was directly dissolved in PBS to a final concentration of 1.3 $\mu \mathrm{g} / \mu \mathrm{l}$; all other drugs were dissolved in 25\% DMSO (10 mM stock solu- tion) and diluted in PBS to a final concentration [aminophosphonopentanoic acid (AP-5), $10 \mu \mathrm{g} / \mu \mathrm{l}$; U0126, $200 \mathrm{ng} / \mu \mathrm{l}$; D-cycloserine, $20 \mu \mathrm{g} / \mu \mathrm{l}$; Trichostatin A, $330 \mu \mathrm{M}$; K252a, $35.7 \mu \mathrm{M})$.

The doses of U0126, D-cycloserine, Trichostatin A, K252a and TrkB-FC were chosen based on pilot experiments and previous studies (Walker et al., 2002; Li et al., 2008; Wang et al., 2010; Whitfield et al., 2011).

Excitotoxic lesions. Rats were anesthetized using sodium pentobarbital ( $55 \mathrm{mg} / \mathrm{kg}$, i.p.), treated with atropine sulfate $(0.2 \mathrm{mg} / \mathrm{kg}$, i.p. $)$, and then placed in a stereotaxic apparatus (Narishige). The scalp was incised and retracted to expose the skull. Small burr holes were drilled through the skull to place a 26 gauge guide cannula using the following coordinates: (1) AP $,+2.8 \mathrm{~mm}, \mathrm{ML}, \pm 0.6 \mathrm{~mm}, \mathrm{DV},-4.5 \mathrm{~mm}$; (2) AP $,+2.8 \mathrm{~mm}, \mathrm{ML}$, $\pm 0.6 \mathrm{~mm}, \mathrm{DV},-4.0 \mathrm{~mm}$. Quinolinic acid $(0.09 \mathrm{M})$ was infused in the $\operatorname{vmPFC}(0.4 \mu \mathrm{l} / \mathrm{site})$, over $2 \mathrm{~min}$ with a 31 gauge injection cannula (1.0 $\mathrm{mm}$ beyond the tip of guide cannula) that was connected to a $10 \mu \mathrm{l}$ microsyringe mounted in the microinfusion pump (Harvard Apparatus). After each infusion, the injection cannula was left in place for $4 \mathrm{~min}$ and then removed slowly. Rats in the sham group were given the same surgical procedures but did not receive microinfusion. All rats were given 5-7 d for postsurgical recovery before behavioral training.

\section{Histology}

After behavior testing, rats were deeply anesthetized with sodium pentobarbital and perfused transcardially with PBS, followed by $4 \%$ Formalin. The brains were removed and stored in a $30 \%$ sucrose solution for $2-3 \mathrm{~d}$. Coronal sections (30 $\mu \mathrm{m}$ thick) were cut on a cryostat (Leica), stained with cresyl violet, and then examined by light microscopy to determine lesion locations or injection sites.

\section{Apparatus and procedures}

The CPA apparatus [62 cm (length) $\times 24 \mathrm{~cm}$ (width) $\times 24 \mathrm{~cm}$ (height)] made of Plexiglas was divided into two equal-sized compartments by a removable partition with an opening $(8 \times 8 \mathrm{~cm})$ at one end, which allowed rats ad libitum access to each compartment. Two compartments were distinguished by visual (white or black) and tactile cue (bar or slick) and provided the distinct contexts that were paired with morphine or saline injections. The apparatus were equipped with infrared photobeams connected to a computer that recorded the rat's location in the chambers.

Training. To determine baseline place preference, the rats were initially placed in the apparatus with the doors removed for 15 min (preconditioning test). Conditioning was performed using an unbiased, counterbalanced protocol, as described in our previous work (Hou et al., 2009). Thirty-three of the 389 rats that were tested for initial CPP preference showed a strong unconditioned aversion $(<180$ in any chamber) and therefore were excluded.

Conditioning took place over the next $2 \mathrm{~d}$. On the first day, the rats were injected with saline $(1 \mathrm{ml} / \mathrm{kg}$, s.c.) and then returned to home cages. Four hours later, they were again given saline and then confined to either compartment in a counterbalanced manner for $30 \mathrm{~min}$. On the second day, the rats were injected with morphine $(10 \mathrm{mg} / \mathrm{kg}$, s.c.) and then returned to their home cages. Four hours later, they were injected with naloxone $(0.3 \mathrm{mg} / \mathrm{kg}$, s.c.) and then confined to the compartment opposite to that on the first day for $30 \mathrm{~min}$. This compartment will be referred to as the "drug treatment-paired compartment." In the post-training testing phase ( $24 \mathrm{~h}$ after the conditioning trial), all rats were allowed to freely explore the entire apparatus for $15 \mathrm{~min}$, and the amount of time spent in each compartment was recorded. CPA score represents the time in the drug treatment-paired compartment during the testing phase minus that during the preconditioning phase.

Extinction. The experiments were performed as described previously (Myers and Carlezon, 2010) with little modification. Briefly, extinction training began $24 \mathrm{~h}$ after the post-training test and consisted of $30 \mathrm{~min}$ confinements in the previously naloxone-paired compartment. On each confinement day, the order of exposure was counterbalanced across rats and reversed relative to the preceding session. Saline was administered immediately before each confinement. Three confinement days were conducted and a 15 min extinction test was performed $24 \mathrm{~h}$ after each confinement day. The rats were decapitated $30 \mathrm{~min}$ after the last test. 


\section{Tissue sample preparation and Histone extraction}

Brains were rapidly removed, frozen in liquid nitrogen, and stored in a $-80^{\circ} \mathrm{C}$ freezer before dissection. Coronal brain sections (1 mm thick) were obtained using a rat brain slicer (Braintree Scientific). The infralimbic (IL) subdivisions of the vmPFC from both hemispheres of rats was isolated from brain slices using a blunt-end, 17 gauge syringe needle ( 1 $\mathrm{mm}$ inner diameter), as described previously (Li et al., 2008). Most rats were decapitated at different time points with anesthesia after the end of the 30 min extinction training. Rats in the control conditions were decapitated at the corresponding time just without receiving extinction training. Tissue punches were homogenized (10-15 s for three times, $5 \mathrm{~s}$ interval) with a sonicator (Sonics \& Materials) in $300 \mu \mathrm{l}$ of lysis buffer (containing, in mm: 20 Tris, pH 7.5, $150 \mathrm{NaCl}, 1 \%$ Triton X-100, 2.5 sodium pyrophosphate, $1 \mathrm{EDTA}, 1 \% \mathrm{Na}_{3} \mathrm{VO}_{4}, 0.5 \mu \mathrm{g} / \mathrm{ml}$ leupeptin, and 1 phenylmethanesulfonyl fluoride; Beyotime Biotechnology). Then, the tissue homogenates were subjected to $10,000 \times g$ centrifugation at $4^{\circ} \mathrm{C}$ for $10 \mathrm{~min}$. The nuclear protein CBP (CREB binding protein) extractions were prepared according to the method of Dignam et al. (1983). The protein concentrations of all samples were determined using the bicinchoninic acid assay (Beyotime Biotechnology). Samples were further diluted in radioimmunoprecipitation assay lysis buffer to equalize the protein concentrations.

Histone extraction was performed as described previously (Roozendaal et al., 2010). Briefly, tissue was homogenized in a hypotonic lysis buffer (containing, in mM: 10 Tris, $\mathrm{pH}$ 8.0, 1 EDTA, 2.5 sodium pyrophosphate, 1 sodium orthovanadate, $1 \mathrm{PMSF}$, and $1 \%$ Halt Protease Cocktail Inhibitor) in $1.5 \mathrm{ml}$ Eppendorf tubes. Lysates were then centrifuged at 14 relative centrifugal force (RCF) for $30 \mathrm{~min}$ at $4^{\circ} \mathrm{C}$. The supernatant was collected, leaving the nuclear pellet for acid extraction ( $1 \mathrm{ml}$ of $0.4 \mathrm{M} \mathrm{H}_{2} \mathrm{SO}_{4}$ ). The nuclear pellet and acid buffer were placed on ice for $20 \mathrm{~min}$ and then centrifuged at $14 \mathrm{RCF}$ for $30 \mathrm{~min}$ at $4^{\circ} \mathrm{C}$. Next, the acid supernatant was collected and ice-cold acetone was added to the pellet and placed on ice for $10 \mathrm{~min}$ before being centrifuged at $14 \mathrm{RCF}$ for $30 \mathrm{~min}$ at $4^{\circ} \mathrm{C}$. Finally, the supernatant was removed and remaining histone pellet was placed at room temperature for $5 \mathrm{~min}$ (for remaining acetone to evaporate) before being resuspended in $9 \mathrm{~m}$ urea.

\section{Western blot assays}

For Western blot analysis, tissue samples and histone extracts from dissected rat vmPFC were used, and the experiments were performed as described previously ( $\mathrm{Li}$ et al., 2008). Briefly, four times loading buffer (16\% glycerol, 20\% mercaptoethanol, 2\% SDS, and $0.05 \%$ bromophenol blue) was added to each sample (3:1; sample: loading buffer) before boiling for $10 \mathrm{~min}$. Samples were cooled and subjected to SDS-PAGE for $\sim 30 \mathrm{~min}$ at $80 \mathrm{~V}$ in stacking gel and $\sim 1 \mathrm{~h}$ at $120 \mathrm{~V}$ in resolving gel, after which proteins were transferred to polyvinylidene difluoride membranes for immunoblotting. For each electrophoresis, increasing amounts of protein pooled from all samples were electrophoresed to produce a standard curve. Proteins were transferred electrophoretically to Immobilon-P transfer membranes (Millipore). Membranes were washed with TBST (Tris-buffered saline plus $0.05 \%$ Tween $20, \mathrm{pH} 7.4)$ and then dipped in blocking buffer $(5 \%$ skimmed dry milk in TBST) $1 \mathrm{~h}$ at room temperature on orbital shaker. The membranes were incubated overnight at $4^{\circ} \mathrm{C}$ with various primary antibodies that included the following: anti-pERK, anti-ERK antibody (Santa Cruz Biotechnology), anti-pCREB, anti-CBP and anti-CREB (Millipore) at a dilution of 1:4000, anti-acetylated histone H3 Lys 9 and anti-acetylated histone H4 Lys 8 antibody (Millipore) at a dilution of $1: 1000$, anti-actin and anti-GAPDH antibody (Sigma) at a dilution of $1: 10,000$ and then incubated with horseradish peroxidase-conjugated secondary antibodies for $1 \mathrm{~h}$ at room temperature. Immunolabeling of membranes was detected via chemiluminescence (ECL, GE Healthcare; SuperSignal, Pierce). Excess mix was dripped off before blots were wrapped with a clean piece of Saran Wrap (no bubbles between blot and wrap) and then exposed against x-ray film (Eastman Kodak) for 5-60 s. The immunopositive signals were quantified by Quantity One software (Bio-Rad).
Chromatin immunoprecipitation and quantitative real-time PCR Chromatin immunoprecipitation (ChIP) was performed following a modification of the Millipore Biotechnology ChIP kit protocol. The infralimbic cortex from both hemispheres of rats was isolated from brain slices as described previously. The tissue was then incubated in $1 \%$ formaldehyde in PBS at room temperature for $20 \mathrm{~min}$, and then the reaction was stopped by adding glycine to a final concentration of $0.125 \mathrm{M}$. The tissue was washed 3 times with an ice-cold PBS containing protease inhibitors (PIs) (Complete Mini Protease Inhibitor Cocktail tablets; Roche). Tissue was homogenized in cell lysis buffer (10 mM Tris, $10 \mathrm{~mm}$ $\mathrm{NaCl}$, and $0.2 \% \mathrm{NP}-40$ ). The homogenate was centrifuged at $5500 \times g$ for $10 \mathrm{~min}$. The supernatant, containing extracellular debris, was decanted, and the pellet was homogenized in SDS lysis buffer with PIs and phosphorylase inhibitors. Next, the extracted chromatin was sheared to 200 1000 bp using the VibraCell sonicator. Lysates were centrifuged at $12,000 \times g$ for $10 \mathrm{~min}$ to pellet debris and then diluted 1:10 in ChIP dilution buffer. Extracts were precleared for $60 \mathrm{~min}$ with $35 \mu \mathrm{l}$ of $50 \%$ suspension of salmon sperm saturated protein A. A total of $10 \mu \mathrm{l}$ of the preimmunoprecipitated lysate was saved as "input." Immunoprecipitations were performed at $4^{\circ} \mathrm{C}$ overnight with primary antibodies (antiacetyl $\mathrm{H} 3$, anti-acetyl $\mathrm{H} 4$, anti-p-CREB, normal mouse IgG, normal rabbit IgG) or no antibody (control). Immune complexes were collected with $60 \mu \mathrm{l}$ of salmon sperm DNA/protein A-agarose beads at $4^{\circ} \mathrm{C}$ for $1 \mathrm{~h}$. The beads were sequentially washed once with low salt, high salt, and $\mathrm{LiCl}$ and washed twice with Tris-EDTA buffers. Immune complexes were eluted from the beads by $200 \mu \mathrm{l}$ of $\mathrm{NaHCO}_{3} / \mathrm{SDS}$ elution buffer and protein-DNA crosslinks were reverted by heating at $65^{\circ} \mathrm{C}$ for $4 \mathrm{~h}$. After proteinase $\mathrm{K}$ digestion $\left(1.5 \mathrm{~h}\right.$ at $\left.45^{\circ} \mathrm{C}\right)$, immunoprecipitated DNA was extracted by the DNA extraction columns provided in the kits, and input DNA was extracted by using a QIAquick PCR purification kit. Immunoprecipitated DNA was subjected to quantitative real-time PCR using primers specific to the rat BDNF promoters. $C_{\mathrm{t}}$ values of each sample and its corresponding input were used to calculate IP DNA quantities as the percentage of input using the following equation: ChIP DNA as a \% of input $=2^{(\Delta \mathrm{Ct})}$.

Quantitative real-time PCR was performed in an Opticon2 (Bio-Rad MJ Research) using SYBR Green PCR Master Mix (Cowin) through 45 PCR cycles $\left(95^{\circ} \mathrm{C}\right.$ for $10 \mathrm{~s}, 60^{\circ} \mathrm{C}$ for $\left.45 \mathrm{~s}\right)$. The threshold cycle for each sample was chosen from the linear range and converted to a starting quantity by interpolation from a standard curve run on the same plate for each set of primers. The mRNA levels were normalized for each well to the GAPDH mRNA levels. Single PCR products were verified by assessing that the melting temperature of the product had a single value.

Primers used in the ChIP assay were: BDNF P1, $5^{\prime}$-TGATCATCACTCACGA CCACG-3' ${ }^{\prime}$ 5'-CAGCCTCTCTGAGCCAGTTACG-3'; BDNF P4, 5'-AAAG CATGCAATGCCCT- $3^{\prime}, 5^{\prime}$-GAGATTTCATGCTAGCTCGC-3'; BDNF exon I, 5'-CTCAAAGGGAAACGTGTCTCT-3', 5'-TCACGTGCTCAAAAGTGT CAG-3'; BDNF exon IV, 5'-TGCGAGTATTACCTCCGCCAT-3'; 5'-TCAC GTGCTCAAAAGTGTCAG-3'; GAPDH, 5'-AACGACCCCTTCATTGAC3', 5'-TCCACGACATACTCAGCAC-3'.

\section{Data analysis}

The data were analyzed with one- or two-way ANOVA followed by Bonferroni's post hoc tests or Student's $t$ tests, when appropriate. Differences with $p<0.05$ were considered statistically significant. The results are presented as mean \pm SEM.

\section{Results}

\section{Lesions of the vmPFC of rats block extinction of morphine withdrawal-induced conditioned place aversion}

Lesion and pharmacological manipulation studies show that the vmPFC is critical for the storage and recall of extinction memories (Milad and Quirk, 2002; Phelps et al., 2004). To determine whether vmPFC is also necessary for extinction of aversive memories associated with morphine withdrawal, we examined the effects of bilateral excitotoxic lesions of vmPFC with quinolinic acid on extinction of CPA behavior. As shown in Figure $1 A$, rats with bilateral excitotoxic lesions of vmPFC showed much higher 
CPA scores than sham-lesion rats, indicating impairment of extinction. Twoway ANOVA assays revealed the significant main effect of extinction training (No-ext vs Ext: $\left.F_{(1,39)}=11.68, p<0.01\right)$ and lesions (Sham vs Lesion: $F_{(3,39)}=11.45, p<0.001$ ), as well as a significant interaction between these factors $\left(F_{(3,39)}=3.49, p<0.05\right)$. The following post hoc test showed that there was significant difference in CPA scores between lesion-extinction rats and shamextinction rats $(p<0.05$ for Test $1, p<$ 0.01 for Test 2 and 3 ). These results demonstrate that the vmPFC is required for extinction of aversive memories associated with morphine withdrawal. Figure $1 B$ shows schematic illustrations of lesion areas in 15 of the rats that received bilateral infusion of quinolinic acid into the vmPFC. Guide cannulas were centered on the IL subdivision of the vmPFC.
A

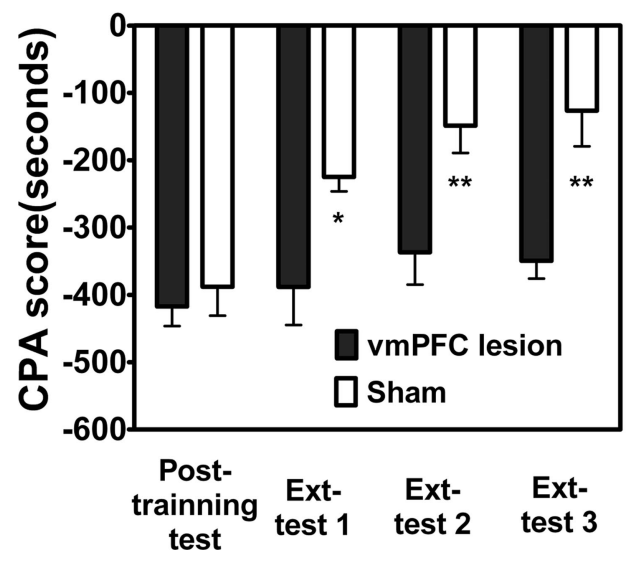

Figure 1. Lesions of rat vmPFC blocked extinction of CPA behavior. $\boldsymbol{A}$, Rats with the vmPFC lesions were unable to extinguish CPA behavior. $\boldsymbol{B}$, Schematic representation of bilateral excitotoxic lesions of the vmPFC. The black areas represent the smallest extent of neuronal damage, and the gray areas represent the largest extent of neuronal damage. Values are expressed as mean \pm SEM $(n=12) .{ }^{*} p<0.05,{ }^{* *} p<0.01$, compared with the corresponding sham-operated groups, two-way ANOVA followed by Bonferroni's post hoc test. Ext, Extinction.

\section{CPA extinction training activates ERK}

and CREB in the vmPFC and intra-vmPFC injection of U0126 prevents activation of ERK and CREB and disrupts extinction of CPA behavior

ERK (extracellular signal-regulated kinase) activation has been described in different brain regions with several learning paradigms (Atkins et al., 1998; Blum et al., 1999; Schafe et al., 2000) and is involved in activity-dependent modulation of synaptic plasticity in various brain areas (English and Sweatt, 1997; Huang et al., 2000), including the mPFC (Otani et al., 1999). ERK inhibitors have been shown to block acquisition in a variety of learning paradigms, including extinction learning (Lu et al., 2001; Hugues et al., 2004; Herry et al., 2006). Thus, we determined whether ERK activation in the vmPFC was involved in the extinction of aversive memories associated with drug withdrawal. To do this, we measured the levels of ERK phosphorylation (pERK) in the vmPFC following extinction training. As shown in Figure $2 \mathrm{~A}$, a significant increase of pERK in the vmPFC was detected at $1 \mathrm{~h}$ after extinction. One-way ANOVA assays revealed a significant main effect of extinction training (Mor vs Mor-Ext: $F_{(3,19)}=7.99$, $p<0.01)$. The following Bonferroni post hoc test showed a significant difference between treatments for pERK $(p<0.01)$. Increase of pERK by extinction training was time-dependent (Fig. $2 B$ ). One-way ANOVA followed by Bonferroni post hoc test also showed that there were significant differences in pERK between $0.5 \mathrm{~h}(p<0.001), 1 \mathrm{~h}(p<0.05)$, and $2 \mathrm{~h}(p>0.05)$ after extinction training. cAMP response element-binding protein (CREB) is an important downstream factor of ERK (West et al., 2001) and plays a crucial role in ERK-mediated synaptic plasticity and long-term memories (Yin et al., 2002; Chwang et al., 2007). Next, we examined the effect of extinction training on CREB activation (phosphorylation at serine 133). As shown in Figure $2 C$, a significant increase in phosphorylation of CREB (pCREB) was also detected in the vmPFC at 0.5 and $1 \mathrm{~h}$ after extinction training $(p<0.05, p<0.001$, one-way ANOVA followed by Bonferroni post hoc test). Intra-vmPFC injection of ERK inhibitor U0126 before extinction training with a dose of $200 \mathrm{ng} / \mu \mathrm{l}$ attenuated extinction training-induced phosphorylation of both $\operatorname{ERK}\left(t_{(1,10)}=3.11, p<0.05\right.$, Student's $t$ test $)$ and $\operatorname{CREB}\left(t_{(1,10)}=\right.$ 2.62, $p<0.05$, Student's $t$ test; Fig. $2 D)$. Accordingly, intravmPFC injection of same dose of ERK inhibitor U0126 before extinction training also impaired extinction of CPA behavior (Fig. 2 E). Two-way ANOVA assays revealed the significant main effect of extinction training $\left(F_{(3,51)}=8.50, p<0.01\right)$ and drug treatment $\left(F_{(1,51)}=8.02, p<0.05\right)$, as well as a significant interaction between these two factors $\left(F_{(3,51)}=4.17, p<0.05\right)$. The following Bonferroni post hoc test showed a significant increase of CPA scores compared with vehicle-injected control group $(p<$ 0.05 ). Figure $2 F$ illustrates the microinjection tips located in the vmPFC. Together, these results suggest that activation of ERKCREB pathway in vmPFC may be involved in the consolidation of extinction of CPA.

Intra-vmPFC injections of D-cycloserine facilitate extinction of CPA behavior and potentiate ERK and CREB activation D-Cycloserine (DCS), a NMDA receptor partial agonist, has been shown to facilitate extinction of CPA behavior (Myers and Carlezon, 2010). To further confirm whether activation ERK and CREB in the vmPFC is required for extinction of CPA behavior, we determined whether facilitating extinction of CPA behavior by DCS was correlated with activation of ERK and CREB. Toward this end, we first examined the effect of DCS on extinction of CPA behavior in our CPA animal model. As shown in Figure $3 A$, intravmPFC injections of DCS $(20 \mu \mathrm{g} / \mu \mathrm{l})$ immediately after extinction training significantly facilitated extinction of CPA behavior. Two-way ANOVA assays revealed the significant main effect of extinction training $\left(F_{(1,16)}=51.56, p<0.01\right)$ and drug treatment $\left(F_{(1,16)}=6.20, p<0.05\right)$, as well as a significant interaction between these two factors $\left(F_{(1,16)}=5.68, p<0.05\right)$. The following post hoc test showed a significant decrease of CPA scores compared with vehicle-injected control group $(p<0.05)$. To further confirm that NMDA receptor signaling is important for extinction of CPA, we detected the effect of AP-5, a selective NMDAR antagonist, on extinction of CPA behavior. As shown in Figure $3 C$, intra-vmPFC injection of AP-5 $(10 \mu \mathrm{g} / \mu \mathrm{l})$ before extinction training significantly blocked extinction of CPA behavior. Twoway ANOVA assays revealed the significant main effect of extinction training $\left(F_{(3,33)}=12.51, p<0.01\right)$ and drug treatment $\left(F_{(1,33)}=6.28, p<0.05\right)$, as well as a significant interaction between these two factors $\left(F_{(3,33)}=5.54, p<0.01\right)$. The following Bonferroni post hoc test showed a significant increase of CPA scores compared with vehicle-injected control group $(p<0.01)$. 
A

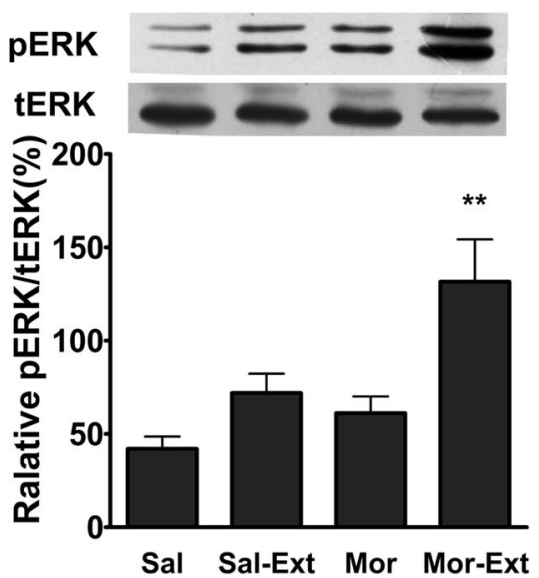

D

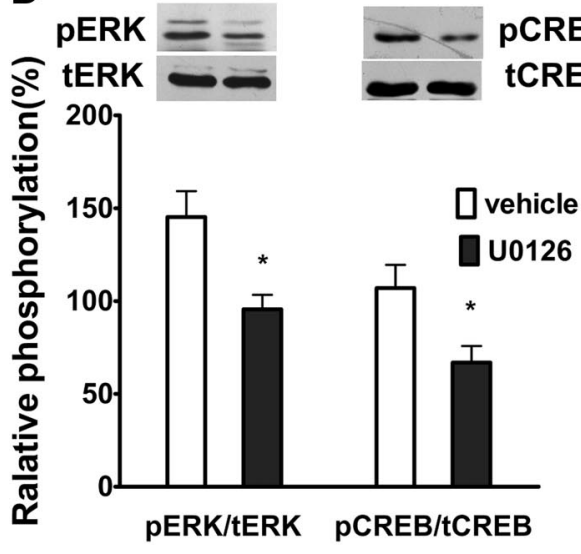

B

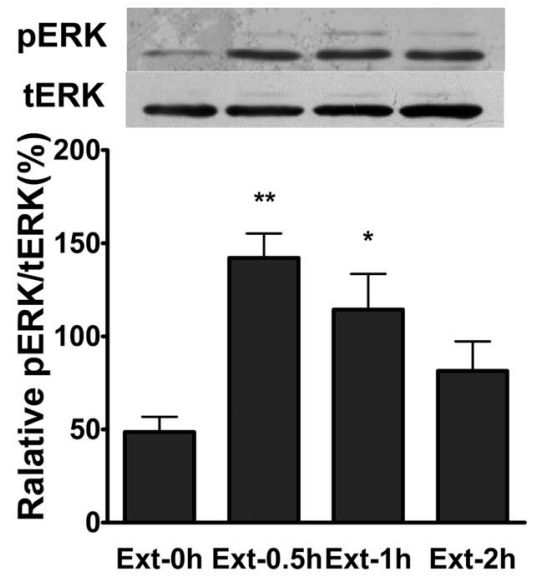

$E$

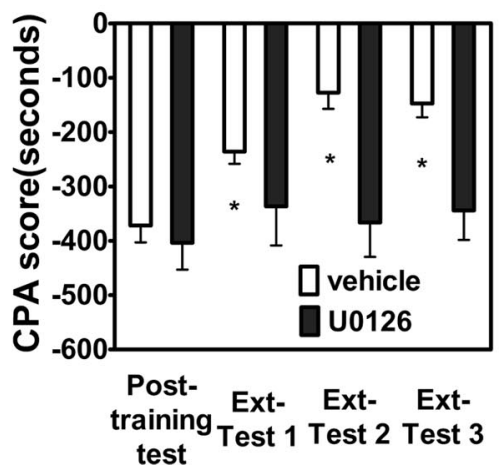

C

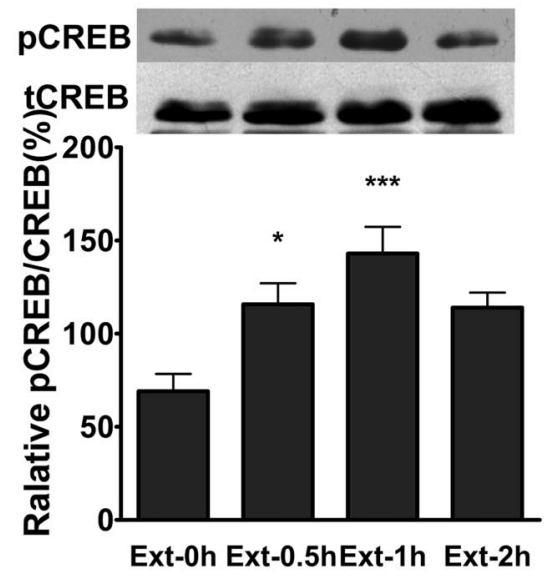

$\mathbf{F}$

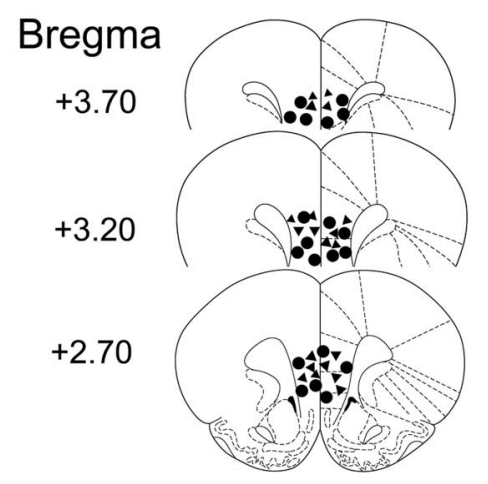

Figure 2. CPA extinction training increased ERK and CREB phosphorylation in the vmPFC, and intra-vmPFC injections of ERK inhibitor U0126 inhibited extinction training-induced ERK and CREB phosphorylation and impaired extinction of CPA behavior. $A$, Increase in ERK phosphorylation could be detected only in extinction of conditioned morphine withdrawal rats but not in other control group rats. $\boldsymbol{B}, \boldsymbol{C}$, Time courses of extinction training-induced ERK and CREB phosphorylation in the vmPFC. $\boldsymbol{D}$, Intra-vmPFC injections of U0126 before extinction training suppressed extinctioninduced ERK and CREB phosphorylation. $E$, Intra-vmPFC injections of U0126 before extinction training blocked extinction of CPA behavior. $F$, Schematic representation of injection sites in the vmPFC for rats used in the experiments $\left(\boldsymbol{\Lambda}\right.$, U0126; $\boldsymbol{O}$, Vehicle). Values are expressed as mean $\pm \operatorname{SEM}(n=6-8) .{ }^{*} p<0.05,{ }^{* *} p<0.01$, compared with the no-extinction groups, one-way ANOVA followed by Bonferroni's post hoc test or Student's $t$ test. Sal, Saline; Mor, morphine; Sal-Ext, saline-extinction; Mor-Ext, morphine-extinction.

Figure $3, B$ and $D$, illustrates the microinjection tips located in the vmPFC.

To determine whether facilitating extinction of CPA by DCS is involved in activation of ERK and CREB, we examined the effects of intra-vmPFC injections of DCS and AP-5 on ERK and CREB phosphorylation in the vmPFC. Intra-vmPFC injections of DCS $(20 \mu \mathrm{g} / \mu \mathrm{l})$ immediately after extinction training significantly potentiated extinction-induced increases in the levels of pERK $\left(t_{(1,10)}=3.09, p<0.01\right.$, Student's $t$ test $)$ and $\operatorname{pCREB}\left(t_{(1,10)}=\right.$ 2.82, $p<0.05$, Student's $t$ test) in the vmPFC compared with vehicle-injected control groups (Fig. $3 E$ ). By contrast, intravmPFC injections of AP-5 $(10 \mu \mathrm{g} / \mu \mathrm{l})$ before extinction training significantly decreased extinction-induced increases in the levels of pERK $\left(t_{(1,10)}=3.77, p<0.01\right.$, Student's $t$ test $)$ and pCREB $\left(t_{(1,10)}=4.14, p<0.01\right.$, Student's $t$ test) in the vmPFC (Fig. $\left.3 F\right)$. Next, we examined the effects of U0126 on DCS-induced increases in pERK and pCREB. Increases in pERK and pCREB by DCS were significantly inhibited by intra-vmPFC injections of U0126 (200 ng/ $\mu \mathrm{l})$ before extinction training (Fig. 3G,H). Oneway ANOVA assays revealed the significant main effects of pERK $\left(F_{(2,17)}=20.20, p<0.001\right)$ and $\operatorname{pCREB}\left(F_{(2,17)}=34.93, p<\right.$ $0.001)$. The following Bonferroni post hoc test showed a significant decreases of pERK and pCREB compared with DCS treat- ment alone $(p<0.05)$. This is consistent with previous findings that DCS facilitates consolidation of extinction fear memory in an ERK-dependent manner (Ledgerwood et al., 2003; Yang and $\mathrm{Lu}, 2005)$. These results suggest that activation of ERK and CREB is involved in facilitating extinction of CPA behavior by DCS, supporting the notion that activation of ERK and CREB is essential for extinction of CPA behavior.

CPA extinction training increases acetylation of histone $\mathrm{H} 3$ and $\mathrm{H} 4$, and $\mathrm{CBP}$ expression in the vmPFC and the augmentation of histone acetylation are potentiated by intravmPFC injections of D-cycloserine

Many forms of learning, including extinction, are dependent on changes in gene expression (Sangha et al., 2003; Lattal et al., 2006). Epigenetic modification of chromatin has been proposed to play a crucial role in regulating gene expression (Levenson and Sweatt, 2005). Previous studies showed that ERK regulated histone acetylation in hippocampus through activation of CREB (Levenson et al., 2004; Chwang et al., 2006; Chandramohan et al., 2008). To further elucidate the mechanisms underlying the extinction of CPA behavior, we asked whether activation of ERK and CREB in the vmPFC induced chromatin modifications. Toward this end, we detected the effects of CPA extinction training 
A

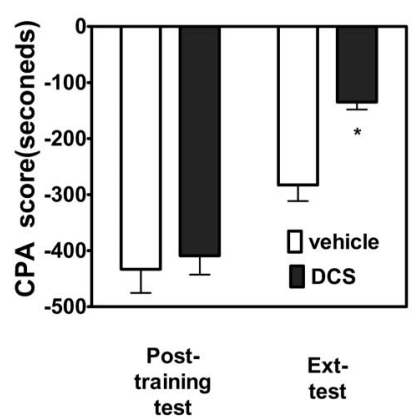

B

Bregma

$+3.70$

$+3.20$

$+2.70$

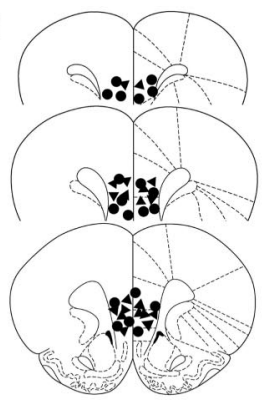

$F$

E

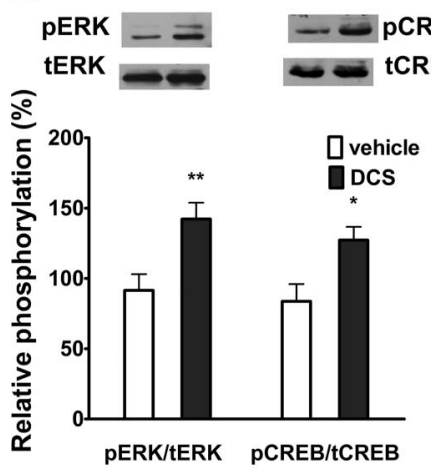

C

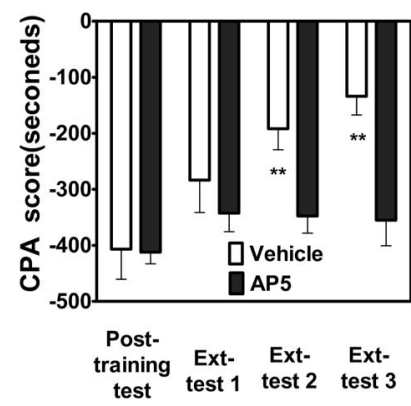

G

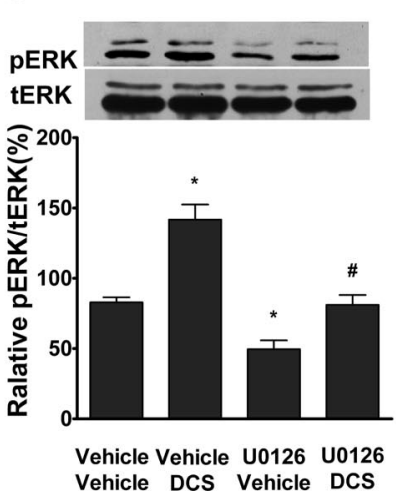

D

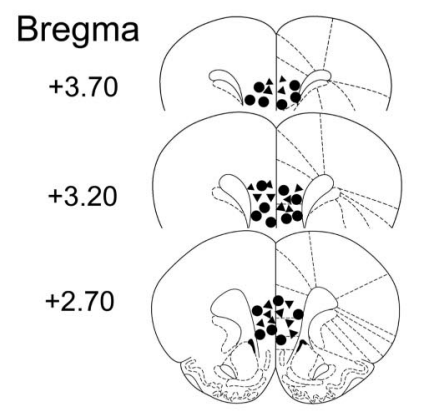

H

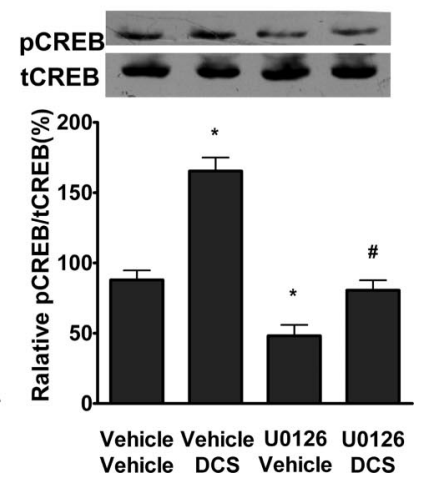

Figure 3. DCS or AP-5 facilitated or blocked extinction of CPA behavior and potentiated or attenuated extinction training-induced ERK and CREB phosphorylation, and U0126 inhibited DCS-induced increases in ERK and CREB phosphorylation. $A$, Intra-vmPFC injections of DCS immediately after extinction training facilitated extinction of CPA behavior. $B$, Schematic representation of injection sites in the vmPFC for rats used in the experiments $(\boldsymbol{\Delta}, \mathrm{DCS} ; \boldsymbol{O}$, Vehicle). C, Intra-vmPFC injections of AP-5 before extinction training blocked extinction of CPA behavior. $\boldsymbol{D}$, Schematic representation of injection sites in the vmPFC for rats used in the experiments $(\boldsymbol{\Lambda}, A P-5 ; \boldsymbol{O}$, Vehicle). $\boldsymbol{E}$, Intra-vmPFC injections of DCS-potentiated ERK and CREB phosphorylation. $\boldsymbol{F}$, Intra-vmPFC injections of AP-5 attenuated ERK and CREB phosphorylation. $\boldsymbol{G}, \boldsymbol{H}$, Intra-vmPFC injections of U0126 before extinction training blocked DCS-induced ERK and CREB phosphorylation. Values are expressed as the mean \pm SEM $(n=6-8) .{ }^{*} p<0.05$, compared with the corresponding vehicle-injected control groups, ${ }^{\#} p<0.05$, compared with the DCS-injected control groups, Student's $t$ test or two-way ANOVA followed by Bonferroni's post hoc test.

on histone acetylation in the vmPFC and determined whether these effects could be suppressed by U0126. Extinction training increased acetylation of histone $\mathrm{H} 3$ at 1,2 , and $3 \mathrm{~h}(p<0.01, p<$ 0.01 and $p<0.05$, respectively, one-way ANOVA followed by Bonferroni post hoc test) and histone $\mathrm{H} 4$ at 1 and $2 \mathrm{~h}(p<0.01$, one-way ANOVA followed by Bonferroni post hoc test; Fig. $4 A, B)$. Intra-vmPFC injections of U0126 before extinction training with a dose of $200 \mathrm{ng} / \mu \mathrm{l}$ inhibited extinction traininginduced acetylation of histone H3 $\left(t_{(1,8)}=2.59, p<0.05\right.$, Student's $t$ test $)$ and histone $\mathrm{H} 4\left(t_{(1,8)}=3.29, p<0.05\right.$, Student's $t$ test; Fig. $4 C$ ). CREB has been shown to induce histone acetylation through the coactivator $\mathrm{CBP}$ and its associated histone acetyltransferase activity (Vecsey et al., 2007). To examine whether or not increased histone acetylation may be related to the enhanced function of CBP, we determined the protein levels of CBP in the vmPFC following extinction training. As shown in Figure $4 D$, CPA extinction training significantly increased the protein levels of CBP in the vmPFC at 1 and $2 \mathrm{~h}$ compared with no-extinction groups $(p<0.001, p<0.05$, respectively, one-way ANOVA followed by Bonferroni post hoc test).

Since DCS potentiates extinction-induced ERK activation, we next examined the effect of DCS on extinction-induced histone acetylation. As shown in Figure 4E, intra-vmPFC injections of DCS immediately after extinction training with a dose of 20 $\mu \mathrm{g} / \mu \mathrm{l}$ potentiated extinction-induced acetylation of histones $\mathrm{H} 3$ $\left(t_{(1,10)}=4.23, p<0.01\right.$, Student's $t$ test $)$ and $\mathrm{H} 4\left(t_{(1,10)}=3.76\right.$, $p<0.01$, Student's $t$ test) and these effects were reversed by intra-vmPFC injections of U0126 before extinction training (Fig.
$4 F, G)$. One-way ANOVA assays revealed the significant main effects acetylation of histone $\mathrm{H} 3\left(F_{(2,17)}=6.00, p<0.05\right)$ and acetylation of histone $\mathrm{H} 4\left(F_{(2,17)}=13.11, p<0.05\right)$. The following Bonferroni post hoc test showed a significant decreases of acetylation of histone $\mathrm{H} 3$ and $\mathrm{H} 4$ compared with treatment with DCS alone $(p<0.05)$. Overall, these results indicate that extinction of CPA is implicated in chromatin modification in the vmPFC in an ERK signaling-dependent manner.

ChIP assays showed a selective increase in acetylation of histones $\mathrm{H} 3$ but not $\mathrm{H} 4$ at and the recruitment of CREB to the promoters of BDFN exon I- but not exon IV-containing transcript in the vmPFC during extinction of CPA

BDNF is critical for learning related synaptic plasticity (Thoenen, 1995; Poo, 2001) and required for extinction of fear memory (Chhatwal et al., 2006; Bredy et al., 2007; Peters et al., 2010). Recently, it was reported that increase of histone acetylation at BDNF gene promoters in prefrontal cortex were associated with extinction of conditioned fear (Bredy et al., 2007). Since CPA extinction training induced acetylation of histone $\mathrm{H} 3$ and histone $\mathrm{H} 4$ (AcH3 and AcH4) in the vmPFC (Fig. 4), we asked whether such chromatin modifications occurred at the promoters of BDNF genes. The rat BDNF gene consists of four distinct exons (Timmusk et al., 1993) and each of these exons is regulated by a specific promoter that is sensitive to epigenetic modification (Kumar et al., 2005; Sadri-Vakili et al., 2010; Schmidt et al., 2012). In the mPFC, exon I and IV-containing BDNF transcripts were shown to be responsive to epigenetic regulation following fear 
A

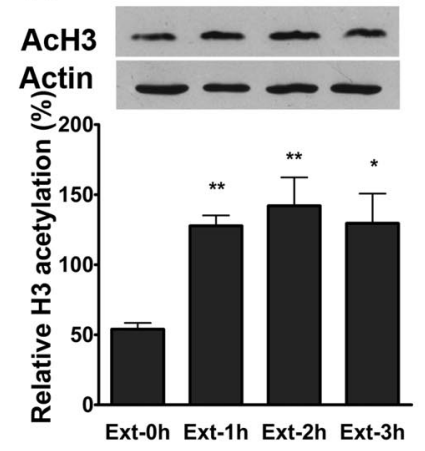

B

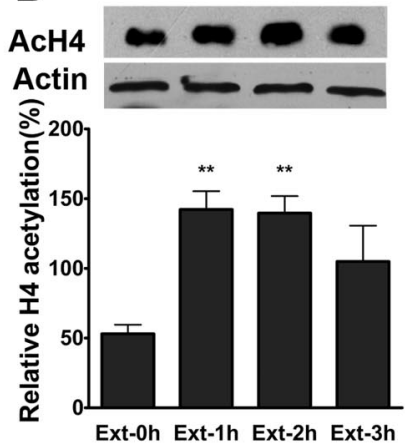

C

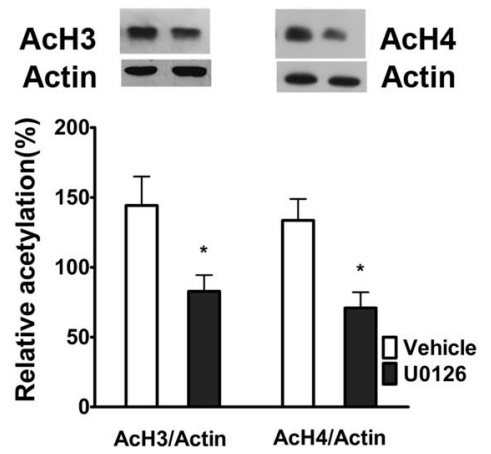

D

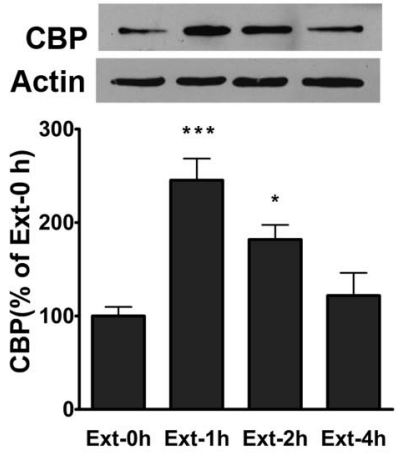

E

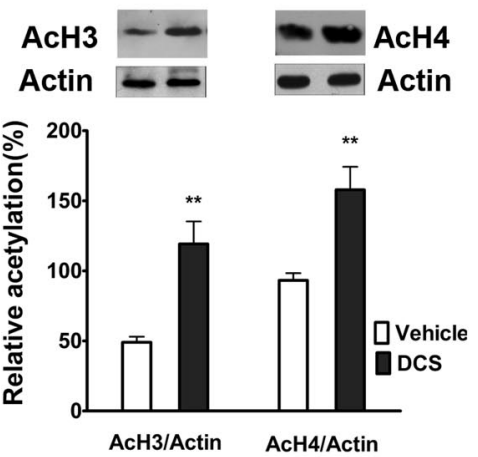

$\mathbf{F}$
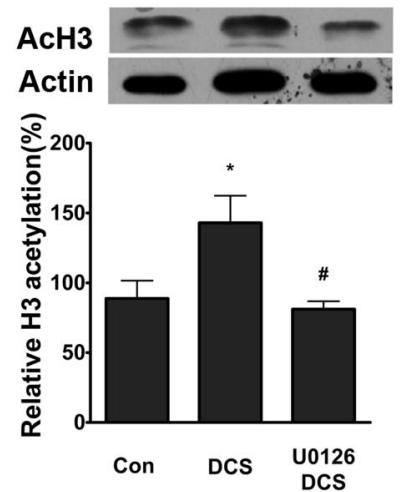

G
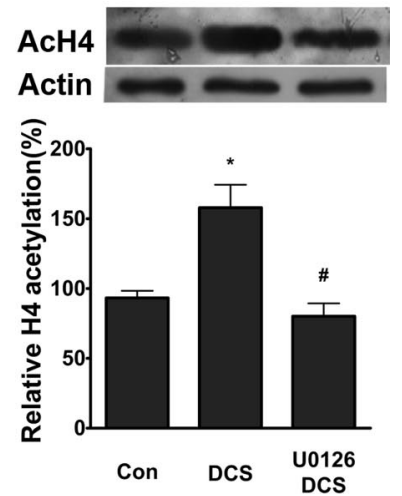

Figure 4. CPA extinction training induced increase of histone acetylation and CBP protein expression in the vmPFC and increased histone acetylation could be potentiated by DCS, but blocked by U0126. A, B , Extinction training increased acetylation of histone $\mathrm{H} 3$ and $\mathrm{H} 4$ in the vmPFC. C, Intra-vmPFC injections of U0126 before extinction training attenuated extinction training-induced acetylation of histone $\mathrm{H} 3$ and H4. D, Extinction training increased CBP protein expression in the vmPFC. $\boldsymbol{E}$, Injections of DCS into the vmPFC immediately after extinction training potentiated acetylation of histone $\mathrm{H} 3$ and $\mathrm{H} 4$. F, G, Intra-vmPFC injections of $\mathrm{U} 0126$ before extinction training inhibited DCS-induced potentiation of acetylation of histone $\mathrm{H} 3$ and $\mathrm{H} 4$. Values are expressed as the mean \pm SEM $(n=6){ }^{*} p<0.05$, compared with the corresponding vehicle-injected control groups; ${ }^{\#} p<0.05$, compared with DCS-injected control groups, Student's $t$ test or two-way ANOVA followed by Bonferroni's post hoc test. AcH3, Acetylation of histone H3; AcH4, Acetylation of histone $\mathrm{H} 4$.

extinction (Bredy et al., 2007). It was also reported that the phosphorylated CREB bound to exon IV to stimulate BDNF gene transcription in the mPFC (Sadri-Vakili et al., 2010). Therefore, we used ChIP to assess the association of $\mathrm{AcH} 3$ and $\mathrm{AcH} 4$ with exon I and IV-containing BDNF transcripts in the vmPFC from rats that underwent extinction training. ChIP assays revealed that there was an increase in the association of $\mathrm{AcH} 3$ but not $\mathrm{AcH} 4$ with BDNF exon I- but not BDNF exon IV-containing transcript in the vmPFC after extinction training (Fig. $5 A, B$ ). Analysis of these data with two-way ANOVA revealed significant main effects of treatment (with or without extinction) $\left(F_{(1,16)}=14.88\right.$, $p<0.01)$ and exon $\left(F_{(1,16)}=8.36 p<0.05\right)$, as well as a significant treatment $\times$ exon interaction $\left(F_{(1,16)}=8.30, p<0.05\right)$. The following Bonferroni's post hoc tests showed that there was a significant difference between with or without extinction for exon I.

CREB is an important transcription factor that modulates the transcription of many genes, including BDNF (Tao et al., 1998; Sadri-Vakili et al., 2010). Several studies have demonstrated that CREB modulates gene transcription through acetylation of histone in a CBP-dependent manner (Levine et al., 2005; Chwang et al., 2007; Vecsey et al., 2007). Given activation of CREB and increases in CBP expression by CPA extinction training, we hypothesized that extinction-induced acetylation of histone $\mathrm{H} 3$ at the promoter region of BDNF was involved in recruiting pCREB. To test this hypothesis, we used ChIP to assess the association of pCREB with BDNF exon I- and IV-containing transcripts in the
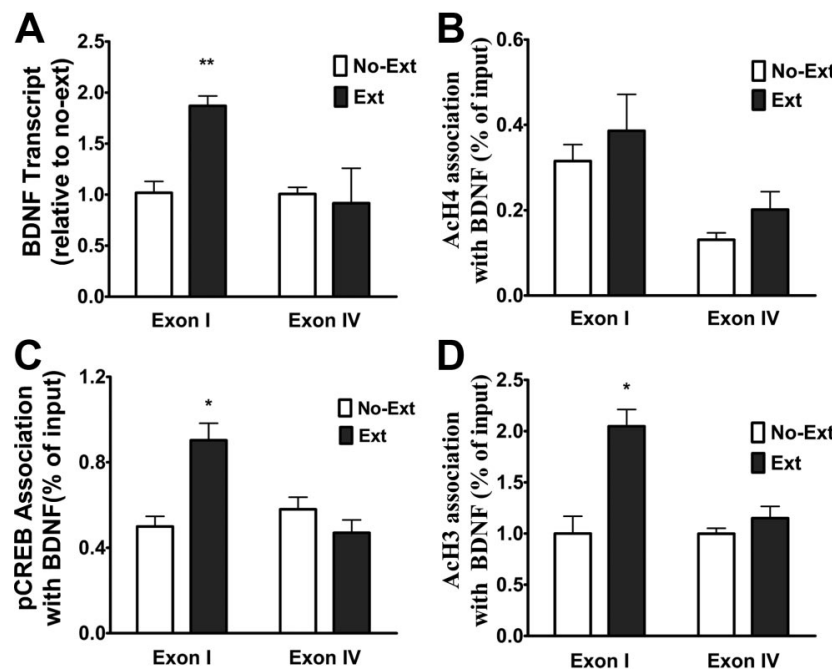

Figure 5. CPA extinction training resulted in increased acetylation of histone $\mathrm{H} 3$ at and recruitment of $p C R E B$ to the promoter of BDNF exon I-containing transcript and increased BDNF exon I transcription in the vmPFC. $A, B$, ChIP assays show increased acetylation of histone $\mathrm{H} 3$ but not histone $\mathrm{H} 4$ at the promoters of BDNF exon I- but not exon IV-containing transcript after extinction training. C, ChIP assays showed increased pCREB recruitment to the promoters of BDNF exon I- but not exon IV-containing transcript after extinction training. $\boldsymbol{D}$, Real-time reverse transcriptase-PCR showed that extinction training selectively increased BDNF exon I transcription. Values are expressed as the mean $\pm \operatorname{SEM}(n=5-6) .{ }^{*} p<0.05,{ }^{* *} p<0.01$, compared with the no-extinction groups, two-way ANOVA followed by Bonferroni's post hoc test. 
vmPFC of rats after extinction training. As shown in Figure $5 C$, extinction training increased pCREB association with BDNF exon I-, but not with exon IVcontaining transcripts in the vmPFC, consistent with association of $\mathrm{AcH} 3$ with BDNF exon I-, but not with exon IV-containing transcripts. Two-way ANOVA assays revealed significant main effects of extinction $\left(F_{(1,13)}=\right.$ $5.81, p<0.05)$ and exon $\left(F_{(1,13)}=8.4\right.$, $p<0.05)$, as well as a significant extinction $\times$ exon interaction $\left(F_{(1,13)}=17.84\right.$, $p<0.001)$. Subsequent pairwise comparisons $(p<0.001)$ showed a significant difference between two treatments for exon I.

Next, we assessed BDNF exon I and IV mRNA expression in the vmPFC of rats that underwent extinction training by using real-time PCR. As shown in Figure 5D, CPA extinction training resulted in a significant increase in BDNF exon I but not exon IV transcription in the vmPFC. Two-way ANOVA analyses revealed significant main effects of extinction treatment $\left(F_{(1,5)}=6.64, p<\right.$ $0.05)$ and exon $\left(F_{(1,5)}=50.27, p<0.001\right)$, as well as a significant interaction between the treatment and exon $\left(F_{(1,5)}=48.30, p<\right.$ 0.001). The following Bonferroni's post hoc tests showed that there was a significant difference between with extinction and without extinction control groups for exon I $(p<0.01)$.

Intra-vmPFC injection of ERK inhibitor U0126 attenuates the association of $\mathrm{AcH} 3$ as well as pCREB with BDNF exon Icontaining transcript and the enhancement of BDNF exon I transcription

Data mentioned above demonstrated that intra-vmPFC injections of U0126 disrupted extinction training-induced phosphorylation of CREB and acetylation of histone $\mathrm{H} 3$ in the mPFC. Thus, we examined the effects of intra-vmPFC injections of $\mathrm{U} 0126$ on extinction training-induced the association of $\mathrm{AcH} 3$ as well as pCREB with BDNF exon I-containing transcript and the enhancement of BDNF exon I transcription. As shown in Figure $6 A$, intra-vmPFC injections of U0126 with a dose of $200 \mathrm{ng} / \mu \mathrm{l}$ before extinction training robustly inhibited the association of AcH3 with BDNF exon I-containing transcript. Two-way ANOVA assays revealed significant main effects of drug treatment $\left(F_{(1,15)}=5.91, p<0.05\right)$ and exon $\left(F_{(1,15)}=20.28, p<\right.$ $0.001)$, as well as a significant treatment $X$ exon interaction $\left(F_{(1,15)}=7.75, p<0.05\right)$. The following Bonferroni's post hoc tests showed that there was a significant difference between U0126 and Vehicle treatment for BDNF exon I-containing transcript $(p<0.01)$.

Likewise, intra-vmPFC injection of U0126 with a dose of $200 \mathrm{ng} / \mu \mathrm{l}$ before extinction training also robustly inhibited association of pCREB with BDNF exon I-containing transcript (Fig. $6 B$ ). Two-way ANOVA assays revealed significant main effects of drug treatment $\left(F_{(1,12)}=10.29, p<0.01\right)$ and exon $\left(F_{(1,12)}=6.35, p<0.05\right)$, as well as a significant extinction $\times$ exon interaction $\left(F_{(1,12)}=7.00, p<0.05\right)$. Subsequent pairwise comparisons $(p<0.01)$ showed a significant difference between U0126 and Vehicle treatments for exon I-containing transcript. Paralleling its inhibitory effects on the association of AcH3 as well as pCREB with BDNF exon I-containing transcript, intra-vmPFC injections of U0126 with a dose of $200 \mathrm{ng} / \mu \mathrm{l}$ before extinction training robustly inhibited enhancement of
B

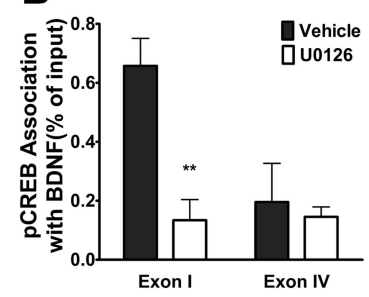

C

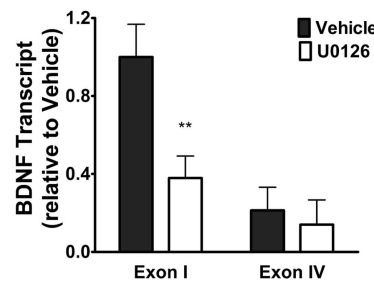

BDon I transcription (Fig. 6C). Two-way ANOVA revealed significant main effects of drug treatment $\left(F_{(1,13)}=6.75, p<\right.$ $0.05)$ and exon $\left(F_{(1,13)}=16.91, p<0.01\right)$, as well as a significant interaction between the treatment and exon $\left(F_{(1,13)}=16.91, p<\right.$ $0.01)$. The following Bonferroni's post hoc tests showed a significant difference between U0126 and Vehicle treatments for exon I $(p<0.001)$.

Intra-vmPFC injections of histone deacetylase inhibitor trichostatin A facilitate extinction of CPA behavior and potentiate extinction-induced histone acetylation and BDNF exon I transcription in the vmPFC

Recent research indicates that HDAC inhibitors facilitate extinction of fear memory (Bredy et al., 2007; Lattal et al., 2007). To further confirm the involvement of changes in histone acetylation in regulation of BDNF mRNA expression and in extinction of CPA behavior, we tested the effects of intra-vmPFC injections of the HDAC inhibitor trichostatin A (TSA) on extinctioninduced histone acetylation and BDNF gene transcription in the vmPFC and on extinction of CPA behavior. We first detected the effect of intra-vmPFC injection of TSA $(330 \mu \mathrm{M})$ on extinctioninduced histone acetylation. As shown in Figure $7 A$, local injection of TSA $(165 \mu \mathrm{m} / \mu \mathrm{l}) 20$ min before extinction training significantly increased extinction-induced acetylation of histone $\mathrm{H} 3\left(t_{(1,10)}=11.83, p<0.001\right.$, Student's $t$ test $)$ and histone H4 $\left(t_{(1,10)}=10.96, p<0.001\right.$, Student's $t$ test $)$ compared with vehicle injection. Next, we assessed the effect of intra-vmPFC injection of TSA on extinction-induced BDNF exon I and IV mRNA expression with the real time PCR. Local injection of TSA before extinction training also significantly potentiated BDNF exon I and IV mRNA expressions compared with local vehicle injection $(p<$ 0.001, $p<0.05$, two-way ANOVA followed by Bonferroni post hoc test; Fig. 7B). Accordingly, behavioral experiments showed that intra-vmPFC injection of TSA $(330 \mu \mathrm{M})$ before extinction training facilitated extinction of CPA behavior (Fig. 7C). Twoway ANOVA assays revealed the significant main effect of extinction training $\left(F_{(1,18)}=48.64, p<0.05\right)$ and drug treatment $\left(F_{(1,18)}=11.61, p<0.01\right)$, as well as a significant interaction between these two factors $\left(F_{(1,18)}=4.59, p<0.05\right)$. The following Bonferroni post hoc test showed a significant decrease of CPA scores compared with vehicle-injected control group $(p<0.05)$. Figure $7 D$ illustrated the microinjection tips located in the vmPFC. These results support that the chromatin modificationmediated increase in expression of BDNF gene in the vmPFC contributes to extinction of CPA behavior. 


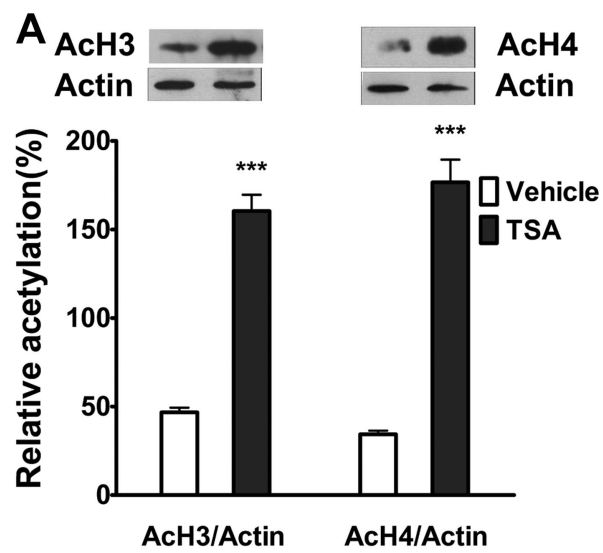

B
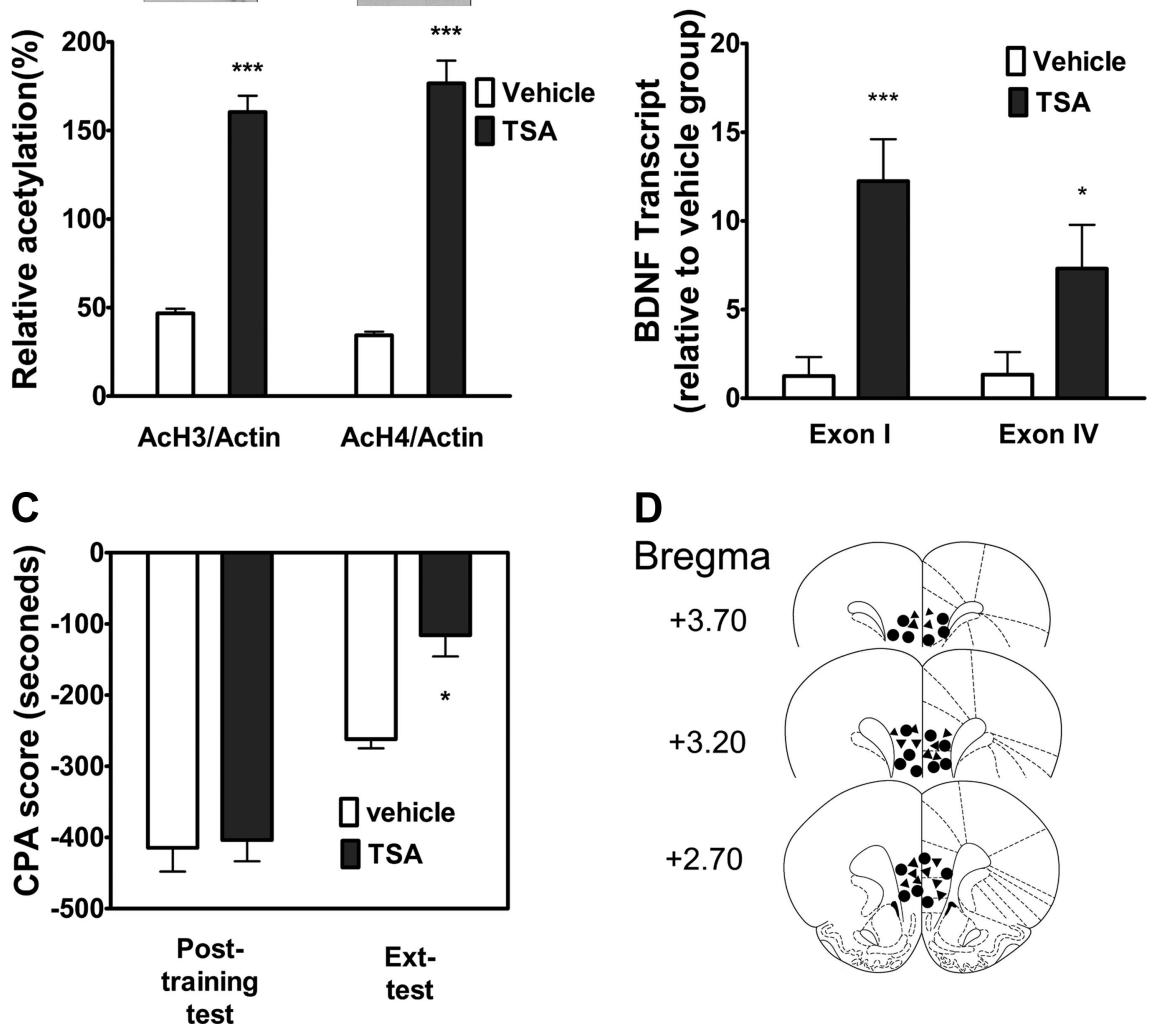

Figure 7. HDAC inhibitor TSA increased histone acetylation as well as BDNF gene transcription in the vmPFC and promoted extinction of CPA behavior. $A$, Intra-vmPFC injections of TSA before extinction training increased the levels of AcH3 and AcH4 ( $n=$ 6). $B, B D N F$ exon I- and exon IV-containing transcripts were significantly increased within the vmPFC after treatment with TSA $(n=5)$. $\boldsymbol{C}$, Injections of TSA into the vmPFC facilitated extinction of CPA behavior $(n=10)$. $\boldsymbol{D}$, Schematic representation of injection sites in the vmPFC for rats used in the experiments ( $\boldsymbol{\Delta}, \mathrm{TSA} ; \boldsymbol{O}$, Vehicle). Values are expressed as the mean \pm SEM. ${ }^{*} p<$ $0.05,{ }^{* *} p<0.001$, compared with the corresponding vehicle-microinjected control groups, Student's $t$ test or one-way ANOVA followed by Bonferroni's post hoc test.

\section{Role of enhancement of BDNF protein expression in the vmPFC in extinction of CPA behavior}

Because BDNF and its receptor TrkB are known to regulate neuronal structure and function and are important for synaptic plasticity (Thoenen, 1995; Poo, 2001) and learning and memory, including fear extinction (Rattiner et al., 2004; Chhatwal et al., 2006; Heldt et al., 2007; Peters et al., 2010), we hypothesized that epigenetic regulation within the vmPFC of BDNF gene expression was necessary for extinction of CPA behavior and that if true, it should be possible to inhibit CPA extinction via direct application of TrkB receptor antagonist K252a and BDNF scavenger TrkB-Fc to block BDNF signaling. To test this hypothesis, we first assessed BDNF protein expression in the vmPFC in response to extinction training. As shown in Figure 8A, extinction training significantly increased BDNF protein expression at $1 \mathrm{~h}, 2$ and $3 \mathrm{~h}$ $(p<0.05$, one-way ANOVA followed by Bonferroni post hoc test), consistent with the enhancement of BDNF mRNA expression in the vmPFC by extinction training. To determine whether increase in BDNF protein levels in the vmPFC were responsible for extinction of CPA behavior, we tested the effects of intravmPFC injections of K252a which is a tyrosine kinase inhibitor with high affinity for all Trk receptors and BDNF scavenger TrkB-Fc on extinction of CPA behavior. As shown in Figure $8 B$, immediately after extinction training intra-vmPFC injection of $\mathrm{K} 252 \mathrm{a}(35.7 \mu \mathrm{M} / \mu \mathrm{l})$ impaired extinction of CPA behavior. Two- way assays revealed significant main effects of k252a treatment $\left(F_{(1,39)}=6.22\right.$, $p<0.05)$ and extinction training $\left(F_{(3,39)}\right.$ $=23.27, p<0.001)$, as well as a significant k252a treatment $\times$ test time interaction $\left(F_{(3,39)}=14.84, p<0.001\right)$. Figure $8 C$ illustrated the microinjection tips located in the vmPFC. Since K252a, a Trkselective tyrosine kinase inhibitor, is not specific for TrkB receptors, we thus further examined the effect of the BDNF scavenger TrkB-Fc on extinction of CPA behavior. Similarly, local injection of TrkB-Fc $(1.3 \mu \mathrm{g} / \mu \mathrm{l})$ into the vmPFC immediately after extinction training also significantly impaired extinction of CPA behavior (Fig. $8 D$ ). Two-way ANOVA assays revealed significant main effects of TrkB-Fc treatment $\left(F_{(1,45)}=5.08, p<\right.$ $0.05)$ and extinction test times $\left(F_{(3,45)}=\right.$ $13.40, p<0.001$ ), as well as a significant interaction between TrkB-Fc treatment and extinction test times $\left(F_{(3,45)}=2.92\right.$, $p<0.05)$. Figure $8 E$ illustrates the microinjection tips located in the vmPFC. Together, these results indicate that increase in BDNF protein expression in the vmPFC plays a crucial role in extinction of CPA behavior.

\section{Discussion}

CPA extinction training results in epigenetic regulation within the vmPFC of BDNF gene transcription

Long-lasting extinction of positive affective memory of drug taking and negative affective memory of drug withdrawal may be important for clinical treatment of drug addiction. Persistent extinction of conditioned responses depends on regulated gene expression (Sangha et al., 2003; Santini et al., 2004; Lattal et al., 2006). Chromatin modification, such as histone acetylation, appears to be a critical mechanism involved in the regulation of gene transcription that may underlie long-term memory formation and longlasting changes in behaviors (Alarcón et al., 2004; Levenson et al., 2004; Renthal and Nestler, 2008). Recent research indicates that HDAC inhibitors facilitate extinction of fear memory (Bredy et al., 2007; Lattal et al., 2007; Bredy and Barad, 2008) and druginduced conditioned place preference (Malvaez et al., 2010; Wang et al., 2010). These studies suggest that extinction learning involves epigenetic regulation of transcription of certain genes that are essential for long-lasting synaptic plasticity and longterm memory.

In support of an important role of epigenetic regulation of gene transcription in extinction learning, this present study demonstrated that CPA extinction training resulted in significant increases in BDNF gene transcription and BDNF protein expression in the vmPFC of rats. Using ChIP assays, we found that extinction-induced increases in BDNF mRNA expression were associated with increased recruitment of CREB to and acetylation of histone $\mathrm{H} 3$ at the promoters of BDNF exon I-containing transcripts in the vmPFC, although Western blot assays showed enhancement of both histone $\mathrm{H} 3$ and histone $\mathrm{H} 4$ 
acetylation in the vmPFC. Discrepantly, a previous study showed that extinction of conditioned fear induced a significant increase in histone $\mathrm{H} 4$ acetylation at the promoters of BDNF exon I and IV-containing transcripts in the mPFC (Bredy et al., 2007). These findings indicate that various extinction paradigms differentially regulate BDNF mRNA expression in the mPFC by exonspecific transcription. Further, we found that intra-vmPFC administration of HDAC inhibitor TSA enhanced extinction-induced histone acetylation as well as BDNF gene transcription in the vmPFC. These results clearly indicate that epigenetic regulation of BDNF gene transcription in the vmPFC is required for the extinction of aversive memory associated with drug withdrawal.

Behavioral consequences of extinctioninduced changes in BDNF transcription within the vmPFC

BDNF is essential for learning related synaptic plasticity and the maintenance of long-term memory. The role of BDNF in fear extinction is well established (Chhatwal et al., 2006; Heldt et al., 2007; Kirtley and Thomas, 2010; Peters et al., 2010). A recent study reported that enhancement of BDNF levels in the IL-mPFC either by direct infusion of BDNF to IL-mPFC or by infusion of BDNF into the hippocampal-IL mPFC pathway induced extinction of fear memory (Peters et al., 2010). Recent evidence also shows that epigenetic regulation within the vmPFC of BDNF gene transcription correlates with fear extinction (Bredy et al., 2007). These studies suggest that elevation of BDNF levels in the vmPFC is critical for the extinction of fear behaviors. The present study demonstrated that CPA extinction training resulted in significant increases in BDNF expression in the vmPFC of rats through epigenetic mechanism. Intra-infralimbic subregion of vmPFC infusion of the Trk receptor antagonist K252a or BDNF scavenger TrkB-Fc disrupted extinction of CPA behavior, indicating that BDNF signaling through TrkB receptors in the vmPFC is required for the extinction of aversive memory associated with drug withdrawal. The vmPFC is composed of the IL and the prelimbic (PL) cortex. Substantial evidence suggests that IL and PL have opposite influences on fear and addiction and have different connections to the amygdala and the nucleus accumbens subregions (for review, see Peters et al., 2009). The present study provides new evidence in support of a critical role of the vmPFC (infralimbic subregion) in extinction learning and memory by showing that the vmPFC is required for extinction of CPA behavior. Moreover, the present study further suggests that epigenetic regulation of BDNF expression in the vmPFC is critical for extinction of CPA behavior.

Additionally, a great body of evidence indicates that BDNF is critically involved in the regulation of cocaine craving and relapse. BDNF in various brain regions differentially regulates cocaine-seeking behaviors. Increases in BDNF protein levels in the nucleus accumbens (NAc) and the ventral tegmental area (VTA) contribute significantly to cocaine reinforcement and the reinstatement of cocaine seeking (Grimm et al., 2003; Lu et al., 2004; Graham et al., 2007). In contrast to its role in the NAc and

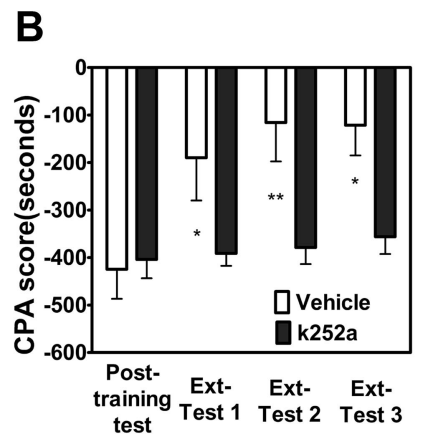

E
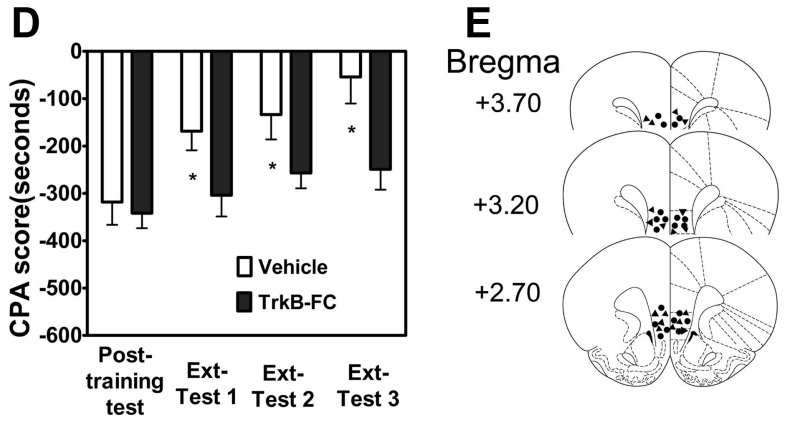

Figure 8. Increase of BDNF protein expression was required for extinction of CPA. $A, B D N F$ protein levels were increased in the , Injection of BDNF scavenger TrkB-FC into the vmPFC blocked extinction of CPA behavior $(n=11)$. $\boldsymbol{E}$, Schemati mean \pm SEM. ${ }^{*} p<0.05,{ }^{* * *} p<0.001$, compared with the corresponding vehicle-microinjected control groups, two-way

the VTA, exogenous BDNF infusions into the dmPFC suppress the reinstatement of cocaine seeking (Berglind et al., 2007, 2009; McGinty et al., 2010; Whitfield et al., 2011). A recent study also reported that cocaine self-administration resulted in increased expression of BDNF in the $\mathrm{dmPFC}$ and knockdown of such BDNF expression in the dmPFC with shRNA increased the cocaine-taking behavior, suggesting that increases in BDNF transcription in the dmPFC may diminish the reinforcing efficacy of cocaine (Sadri-Vakili et al., 2010). Correspondingly, we found that augmentation of BDNF expression in the vmPFC extinguished aversive affective memory of drug withdrawal. Given an important role of negative affective memory in the maintenance of drug seeking behavior, our findings may give a possible explanation why increase in BDNF levels in the vmPFC lead to attenuating the reinstatement of drug seeking.

Signaling pathways whereby CPA extinction training induces histone acetylation at BDNF exon I-containing promoters

ERK plays an important role in long-term synaptic plasticity (Thomas and Huganir, 2004) and it has been established as a potent regulator of gene transcription in long-term memory formation (Impey et al., 1998; Miller and Marshall, 2005). Recently, ERK was shown to regulate histone acetylation in hippocampus (Levenson et al., 2004; Chwang et al., 2006; Chandramohan et al., 2008). Consistently, the current study showed that CPA extinction training induced activation of ERK in the vmPFC. Infusion of ERK inhibitor U0126 into the VmPFC inhibited CPA extinction training-induced enhancement of acetylation of histone $\mathrm{H} 3$ at BDNF exon I-containing promoters, indicating that ERK was an important regulator of histone acetylation. CREB is an important downstream effector of ERK in the regulation of gene transcription (Impey et al., 1998; Chwang et al., 2007). ERK can exert 
transcriptional regulation effects by controlling the phosphorylation of CREB via mitogen- and stress-activated protein kinase 1 (MSK1) (Brami-Cherrier et al., 2005; Chwang et al., 2007). CREB is thought to activate transcription through recruiting the coactivator CBP (Hu et al., 1999; Korzus et al., 2004; Pandey et al., 2008). The recruited CBP has intrinsic histone acetyltransferase activity and can acetylate lysine residues within histones helps to remodel chromatin structure into a form that is accessible to active transcription (Chrivia et al., 1993; Alarcón et al., 2004). CBP has been shown to be necessary for long-lasting forms of transcription-dependent synaptic plasticity and long-term memory (Alarcón et al., 2004; Korzus et al., 2004; Oliveira et al., 2007).

In this study, we found that CPA extinction training induced CREB phosphorylation and increased the association of phosphorylated CREB with BDNF exon I-containing promoters and that CPA extinction training also induced enhancement of CBP protein expression in the vmPFC, suggestive of the possibility that CPA extinction training-induced histone acetylation may be involved in CREB recruitment of CBP. We further found that infusion of U0126 into the vmPFC suppressed extinctioninduced CREB phosphorylation and the association of phosphorylated CREB with BDNF exon I-containing promoters and disrupted extinction training-induced increase in BDNF gene transcription and decrease in CPA behavior. These results support that ERK-CREB signaling pathways are involved in CPA extinction training-induced chromatin modification. Further, given the observations that infusion of DCS, a NMDA receptor partial agonist, into the vmPFC mimics CPA behavioral extinction which activates ERK and CREB, induces histone acetylation and attenuates CPA behavior, our findings also suggest that CPA extinction training-induced activation of ERK-CREB signaling pathways in the vmPFC may be in a NMDA receptor-dependent manner as reported in the hippocampus by previous studies (Levenson et al., 2004; Chandramohan et al., 2007, 2008).

\section{Conclusions}

The present study demonstrates that CPA extinction training increases BDNF mRNA expression in the vmPFC through chromatin modification, which is critical for the extinction of aversive memory associated with drug withdrawal. Specifically, following CPA extinction training the chromatin associated with BDNF exon I transcript increases the association with phosphorylated CREB and becomes acetylated, which remodels chromatin structure into a form that is accessible to active transcription. This study also suggests that CPA extinction training-induced chromatin modification of BDNF gene transcription in the vmPFC is trigged by activation of ERK-CREB signaling pathways perhaps in a NMDA receptor-dependent manner. Our results provide the first evidence that chromatin regulation of BDNF transcription in the vmPFC is an important mechanism that is involved in the extinction of aversive memories associated with morphine withdrawal. Our results also define a series of molecular mechanisms whereby extinction training leads to chromatin remodeling. Our findings may facilitate the development of treatments for drug craving and relapse.

\section{References}

Alarcón JM, Malleret G, Touzani K, Vronskaya S, Ishii S, Kandel ER, Barco A (2004) Chromatin acetylation, memory, and LTP are impaired in $\mathrm{CBP}+/-$ mice: a model for the cognitive deficit in Rubinstein-Taybi syndrome and its amelioration. Neuron 42:947-959.

Atkins CM, Selcher JC, Petraitis JJ, Trzaskos JM, Sweatt JD (1998) The MAPK cascade is required for mammalian associative learning. Nat Neurosci 1:602-609.
Azar MR, Jones BC, Schulteis G (2003) Conditioned place aversion is a highly sensitive index of acute opioid dependence and withdrawal. Psychopharmacology (Berl) 170:42-50.

Berglind WJ, See RE, Fuchs RA, Ghee SM, Whitfield TW Jr, Miller SW, McGinty JF (2007) A BDNF infusion into the medial prefrontal cortex suppresses cocaine seeking in rats. Eur J Neurosci 26:757-766.

Berglind WJ, Whitfield TW Jr, LaLumiere RT, Kalivas PW, McGinty JF (2009) A single intra-PFC infusion of BDNF prevents cocaine-induced alterations in extracellular glutamate within the nucleus accumbens. J Neurosci 29:3715-3719.

Blum S, Moore AN, Adams F, Dash PK (1999) A mitogen-activated protein kinase cascade in the CA1/CA2 subfield of the dorsal hippocampus is essential for long-term spatial memory. J Neurosci 19:3535-3544.

Brami-Cherrier K, Valjent E, Hervé D, Darragh J, Corvol JC, Pages C, Arthur SJ, Simon AJ, Girault JA, Caboche J (2005) Parsing molecular and behavioral effects of cocaine in mitogen- and stress-activated protein kinase-1-deficient mice. J Neurosci 25:11444-11454.

Bredy TW, Barad M (2008) The histone deacetylase inhibitor valproic acid enhances acquisition, extinction, and reconsolidation of conditioned fear. Learn Mem 15:39-45.

Bredy TW, Wu H, Crego C, Zellhoefer J, Sun YE, Barad M (2007) Histone modifications around individual BDNF gene promoters in prefrontal cortex are associated with extinction of conditioned fear. Learn Mem 14:268-276.

Chandramohan Y, Droste SK, Reul JM (2007) Novelty stress induces phospho-acetylation of histone $\mathrm{H} 3$ in rat dentate gyrus granule neurons through coincident signalling via the $\mathrm{N}$-methyl-D-aspartate receptor and the glucocorticoid receptor: relevance for c-fos induction. J Neurochem 101:815-828.

Chandramohan Y, Droste SK, Arthur JS, Reul JM (2008) The forced swimming-induced behavioural immobility response involves histone $\mathrm{H} 3$ phospho-acetylation and c-Fos induction in dentate gyrus granule neurons via activation of the $N$-methyl-D-aspartate/extracellular signalregulated kinase/mitogen- and stress-activated kinase signalling pathway. Eur J Neurosci 27:2701-2713.

Chhatwal JP, Stanek-Rattiner L, Davis M, Ressler KJ (2006) Amygdala BDNF signaling is required for consolidation but not encoding of extinction. Nat Neurosci 9:870-872.

Chrivia JC, Kwok RP, Lamb N, Hagiwara M, Montminy MR, Goodman RH (1993) Phosphorylated CREB binds specifically to the nuclear protein CBP. Nature 365:855-859.

Chwang WB, O’Riordan KJ, Levenson JM, Sweatt JD (2006) ERK/MAPK regulates hippocampal histone phosphorylation following contextual fear conditioning. Learn Mem 13:322-328.

Chwang WB, Arthur JS, Schumacher A, Sweatt JD (2007) The nuclear kinase mitogen- and stress-activated protein kinase 1 regulates hippocampal chromatin remodeling in memory formation. J Neurosci $27: 12732-12742$

De Vries TJ, Shippenberg TS (2002) Neural systems underlying opiate addiction. J Neurosci 22:3321-3325.

Dignam JD, Lebovitz RM, Roeder RG (1983) Accurate transcription initiation by RNA polymerase II in a soluble extract from isolated mammalian nuclei. Nucleic Acids Res 11:1475-1489.

English JD, Sweatt JD (1997) A requirement for the mitogen-activated protein kinase cascade in hippocampal long term potentiation. J Biol Chem 272:19103-19106.

Feltenstein MW, See RE (2007) NMDA receptor blockade in the basolateral amygdala disrupts consolidation of stimulus-reward memory and extinction learning during reinstatement of cocaine-seeking in an animal model of relapse. Neurobiol Learn Mem 88:435-444.

Graham DL, Edwards S, Bachtell RK, DiLeone RJ, Rios M, Self DW (2007) Dynamic BDNF activity in nucleus accumbens with cocaine use increases self-administration and relapse. Nat Neurosci 10:1029-1037.

Grimm JW, Lu L, Hayashi T, Hope BT, Su TP, Shaham Y (2003) Timedependent increases in brain-derived neurotrophic factor protein levels within the mesolimbic dopamine system after withdrawal from cocaine: implications for incubation of cocaine craving. J Neurosci 23:742-747.

Heldt SA, Stanek L, Chhatwal JP, Ressler KJ (2007) Hippocampus-specific deletion of BDNF in adult mice impairs spatial memory and extinction of aversive memories. Mol Psychiatry 12:656-670.

Herry C, Trifilieff P, Micheau J, Lüthi A, Mons N (2006) Extinction of au- 
ditory fear conditioning requires MAPK/ERK activation in the basolateral amygdala. Eur J Neurosci 24:261-269.

Hou YY, Lu B, Li M, Liu Y, Chen J, Chi ZQ, Liu JG (2009) Involvement of actin rearrangements within the amygdala and the dorsal hippocampus in aversive memories of drug withdrawal in acute morphine-dependent rats. J Neurosci 29:12244-12254.

Hsu E, Packard MG (2008) Medial prefrontal cortex infusions of bupivacaine or AP-5 block extinction of amphetamine conditioned place preference. Neurobiol Learn Mem 89:504-512.

Huang YY, Martin KC, Kandel ER (2000) Both protein kinase A and mitogen-activated protein kinase are required in the amygdala for the macromolecular synthesis-dependent late phase of long-term potentiation. J Neurosci 20:6317-6325.

Hu SC, Chrivia J, Ghosh A (1999) Regulation of CBP-mediated transcription by neuronal calcium signaling. Neuron 22:799-808.

Hugues S, Deschaux O, Garcia R (2004) Postextinction infusion of a mitogen-activated protein kinase inhibitor into the medial prefrontal cortex impairs memory of the extinction of conditioned fear. Learn Mem 11:540-543.

Hutcheson DM, Everitt BJ, Robbins TW, Dickinson A (2001) The role of withdrawal in heroin addiction: enhances reward or promotes avoidance? Nat Neurosci 4:943-947.

Impey S, Obrietan K, Wong ST, Poser S, Yano S, Wayman G, Deloulme JC, Chan G, Storm DR (1998) Cross talk between ERK and PKA is required for $\mathrm{Ca}^{2+}$ stimulation of CREB-dependent transcription and ERK nuclear translocation. Neuron 21:869-883.

Kenny PJ, Chen SA, Kitamura O, Markou A, Koob GF (2006) Conditioned withdrawal drives heroin consumption and decreases reward sensitivity. J Neurosci 26:5894-5900.

Kirtley A, Thomas KL (2010) The exclusive induction of extinction is gated by BDNF. Learn Mem 17:612-619.

Koob GF, Le Moal M (2005) Plasticity of reward neurocircuitry and the "dark side" of drug addiction. Nat Neurosci 8:1442-1444.

Korzus E, Rosenfeld MG, Mayford M (2004) CBP histone acetyltransferase activity is a critical component of memory consolidation. Neuron 42:961972.

Kumar A, Choi KH, Renthal W, Tsankova NM, Theobald DE, Truong HT, Russo SJ, Laplant Q, Sasaki TS, Whistler KN, Neve RL, Self DW, Nestler EJ (2005) Chromatin remodeling is a key mechanism underlying cocaineinduced plasticity in striatum. Neuron 48:303-314.

Lattal KM, Radulovic J, Lukowiak K (2006) Extinction: [corrected] does it or doesn't it? The requirement of altered gene activity and new protein synthesis. Biol Psychiatry 60:344-351.

Lattal KM, Barrett RM, Wood MA (2007) Systemic or intrahippocampal delivery of histone deacetylase inhibitors facilitates fear extinction. Behav Neurosci 121:1125-1131.

Ledgerwood L, Richardson R, Cranney J (2003) Effects of D-cycloserine on extinction of conditioned freezing. Behav Neurosci 117:341-349.

Levenson JM, Sweatt JD (2005) Epigenetic mechanisms in memory formation. Nat Rev Neurosci 6:108-118.

Levenson JM, O'Riordan KJ, Brown KD, Trinh MA, Molfese DL, Sweatt JD (2004) Regulation of histone acetylation during memory formation in the hippocampus. J Biol Chem 279:40545-40559.

Levine AA, Guan Z, Barco A, Xu S, Kandel ER, Schwartz JH (2005) CREBbinding protein controls response to cocaine by acetylating histones at the fosB promoter in the mouse striatum. Proc Natl Acad Sci U S A 102: 19186-19191.

Li YQ, Li FQ, Wang XY, Wu P, Zhao M, Xu CM, Shaham Y, Lu L (2008) Central amygdala extracellular signal-regulated kinase signaling pathway is critical to incubation of opiate craving. J Neurosci 28:13248-13257.

Lu KT, Walker DL, Davis M (2001) Mitogen-activated protein kinase cascade in the basolateral nucleus of amygdala is involved in extinction of fear-potentiated startle. J Neurosci 21:RC162(1-5).

Lu L, Dempsey J, Liu SY, Bossert JM, Shaham Y (2004) A single infusion of brain-derived neurotrophic factor into the ventral tegmental area induces long-lasting potentiation of cocaine seeking after withdrawal. J Neurosci 24:1604-1611.

Malvaez M, Sanchis-Segura C, Vo D, Lattal KM, Wood MA (2010) Modulation of chromatin modification facilitates extinction of cocaine-induced conditioned place preference. Biol Psychiatry 67:36-43.

Malvaez M, Mhillaj E, Matheos DP, Palmery M, Wood MA (2011) CBP in the nucleus accumbens regulates cocaine-induced histone acetylation and is critical for cocaine-associated behaviors. J Neurosci 31:16941-16948.

McGinty JF, Whitfield TW Jr, Berglind WJ (2010) Brain-derived neurotrophic factor and cocaine addiction. Brain Res 1314:183-193.

Milad MR, Quirk GJ (2002) Neurons in medial prefrontal cortex signal memory for fear extinction. Nature 420:70-74.

Miller CA, Marshall JF (2005) Molecular substrates for retrieval and reconsolidation of cocaine-associated contextual memory. Neuron 47:873884.

Myers KM, Carlezon WA Jr (2010) D-cycloserine facilitates extinction of naloxone-induced conditioned place aversion in morphine-dependent rats. Biol Psychiatry 67:85-87.

Oliveira AM, Wood MA, McDonough CB, Abel T (2007) Transgenic mice expressing an inhibitory truncated form of $\mathrm{p} 300$ exhibit long-term memory deficits. Learn Mem 14:564-572.

Otani S, Auclair N, Desce JM, Roisin MP, Crépel F (1999) Dopamine receptors and groups I and II mGluRs cooperate for long-term depression induction in rat prefrontal cortex through converging postsynaptic activation of MAP kinases. J Neurosci 19:9788-9802.

Pandey SC, Ugale R, Zhang H, Tang L, Prakash A (2008) Brain chromatin remodeling: a novel mechanism of alcoholism. J Neurosci 28:3729-3737.

Peters J, Kalivas PW, Quirk GJ (2009) Extinction circuits for fear and addiction overlap in prefrontal cortex. Learn Mem 16:279-288.

Peters J, Dieppa-Perea LM, Melendez LM, Quirk GJ (2010) Induction of fear extinction with hippocampal-infralimbic BDNF. Science 328: $1288-1290$.

Phelps EA, Delgado MR, Nearing KI, LeDoux JE (2004) Extinction learning in humans: role of the amygdala and vmPFC. Neuron 43:897-905.

Poo MM (2001) Neurotrophins as synaptic modulators. Nat Rev Neurosci 2:24-32.

Quirk GJ, Mueller D (2008) Neural mechanisms of extinction learning and retrieval. Neuropsychopharmacology 33:56-72.

Rattiner LM, Davis M, French CT, Ressler KJ (2004) Brain-derived neurotrophic factor and tyrosine kinase receptor B involvement in amygdaladependent fear conditioning. J Neurosci 24:4796-4806.

Renthal W, Nestler EJ (2008) Epigenetic mechanisms in drug addiction. Trends Mol Med 14:341-350.

Renthal W, Maze I, Krishnan V, Covington HE 3rd, Xiao G, Kumar A, Russo SJ, Graham A, Tsankova N, Kippin TE, Kerstetter KA, Neve RL, Haggarty SJ, McKinsey TA, Bassel-Duby R, Olson EN, Nestler EJ (2007) Histone deacetylase 5 epigenetically controls behavioral adaptations to chronic emotional stimuli. Neuron 56:517-529.

Romieu P, Host L, Gobaille S, Sandner G, Aunis D, Zwiller J (2008) Histone deacetylase inhibitors decrease cocaine but not sucrose selfadministration in rats. J Neurosci 28:9342-9348.

Roozendaal B, Hernandez A, Cabrera SM, Hagewoud R, Malvaez M, Stefanko DP, Haettig J, Wood MA (2010) Membrane-associated glucocorticoid activity is necessary for modulation of long-term memory via chromatin modification. J Neurosci 30:5037-5046.

Sadri-Vakili G, Kumaresan V, Schmidt HD, Famous KR, Chawla P, Vassoler FM, Overland RP, Xia E, Bass CE, Terwilliger EF, Pierce RC, Cha JH (2010) Cocaine-induced chromatin remodeling increases brain-derived neurotrophic factor transcription in the rat medial prefrontal cortex, which alters the reinforcing efficacy of cocaine. J Neurosci 30:1173511744.

Sangha S, Scheibenstock A, Morrow R, Lukowiak K (2003) Extinction requires new RNA and protein synthesis and the soma of the cell right pedal dorsal 1 in Lymnaea stagnalis. J Neurosci 23:9842-9851.

Santini E, Ge H, Ren K, Peña de Ortiz S, Quirk GJ (2004) Consolidation of fear extinction requires protein synthesis in the medial prefrontal cortex. J Neurosci 24:5704-5710.

Schafe GE, Atkins CM, Swank MW, Bauer EP, Sweatt JD, LeDoux JE (2000) Activation of ERK/MAP kinase in the amygdala is required for memory consolidation of pavlovian fear conditioning. J Neurosci 20:8177-8187.

Schmidt HD, Sangrey GR, Darnell SB, Schassburger RL, Cha JH, Pierce RC, Sadri-Vakili G (2012) Increased brain-derived neurotrophic factor (BDNF) expression in the ventral tegmental area during cocaine abstinence is associated with increased histone acetylation at BDNF exon I-containing promoters. J Neurochem 120:202-209.

Stinus L, Caille S, Koob GF (2000) Opiate withdrawal-induced place aversion lasts for up to 16 weeks. Psychopharmacology (Berl) 149: $115-120$. 
Tao X, Finkbeiner S, Arnold DB, Shaywitz AJ, Greenberg ME (1998) $\mathrm{Ca}^{2+}$ influx regulates BDNF transcription by a CREB family transcription factor-dependent mechanism. Neuron 20:709-726.

Taylor JR, Olausson P, Quinn JJ, Torregrossa MM (2009) Targeting extinction and reconsolidation mechanisms to combat the impact of drug cues on addiction. Neuropharmacology 56 [Suppl 1]:186-195.

Thoenen H (1995) Neurotrophins and neuronal plasticity. Science 270: 593-598.

Thomas GM, Huganir RL (2004) MAPK cascade signalling and synaptic plasticity. Nat Rev Neurosci 5:173-183.

Timmusk T, Palm K, Metsis M, Reintam T, Paalme V, Saarma M, Persson H (1993) Multiple promoters direct tissue-specific expression of the rat BDNF gene. Neuron 10:475-489.

Torregrossa MM, Sanchez H, Taylor JR (2010) D-cycloserine reduces the context specificity of pavlovian extinction of cocaine cues through actions in the nucleus accumbens. J Neurosci 30:10526-10533.

Vecsey CG, Hawk JD, Lattal KM, Stein JM, Fabian SA, Attner MA, Cabrera SM, McDonough CB, Brindle PK, Abel T, Wood MA (2007) Histone deacetylase inhibitors enhance memory and synaptic plasticity via CREB:CBP-dependent transcriptional activation. J Neurosci 27: $6128-6140$.
Walker DL, Ressler KJ, Lu KT, Davis M (2002) Facilitation of conditioned fear extinction by systemic administration or intra-amygdala infusions of D-cycloserine as assessed with fear-potentiated startle in rats. J Neurosci 22:2343-2351.

Wang R, Zhang Y, Qing H, Liu M, Yang P (2010) The extinction of morphine-induced conditioned place preference by histone deacetylase inhibition. Neurosci Lett 483:137-142.

West AE, Chen WG, Dalva MB, Dolmetsch RE, Kornhauser JM, Shaywitz AJ, Takasu MA, Tao X, Greenberg ME (2001) Calcium regulation of neuronal gene expression. Proc Natl Acad Sci U S A 98:11024-11031.

Whitfield TW Jr, Shi X, Sun WL, McGinty JF (2011) The suppressive effect of an intra-prefrontal cortical infusion of BDNF on cocaine-seeking is trk receptor and extracellular signal-regulated protein kinase mitogenactivated protein kinase dependent. J Neurosci 31:834-842.

Yang YL, Lu KT (2005) Facilitation of conditioned fear extinction by $\mathrm{d}$-cycloserine is mediated by mitogen-activated protein kinase and phosphatidylinositol 3-kinase cascades and requires de novo protein synthesis in basolateral nucleus of amygdala. Neuroscience 134:247-260.

Yin Y, Edelman GM, Vanderklish PW (2002) The brain-derived neurotrophic factor enhances synthesis of Arc in synaptoneurosomes. Proc Natl Acad Sci U S A 99:2368-2373. 